\title{
Recommended approaches for smart grid development in China
}

5.1 Define a long-term strategy for the electricity sector and establish an independent and powerful regulator - 81

5.1.1 Background - 81

5.1.2 International practice - 83

5.1.3 Recommended approach for China - 84

5.2 Create level playing fields for access to power system infrastructure and information - 85

5.2.1 Background - 85

5.2.2 International practice -87

5.2.3 Recommended approach for China - 90

5.3 Introduce network regulation for efficient investment incentives for electricity grid expansion and upgrade - 90

5.3.1 Background - 91

5.3.2 International practice - 92

5.3.3 Recommended approach for China - 93

5.4 Coordinate network expansion planning for electricity grid expansion and upgrade - 94

5.4.1 Background - 94

5.4.2 International practice - 95

5.4.3 Recommended approach for China - 97

5.5 Improve grid integration of RES - 98

5.5.1 Background - 99

5.5.2 International practice - 100

5.5.3 Recommended approach for China - 103 
5.6 Optimize the balancing of electricity generation and consumption - 104

5.6.1 Background - 104

5.6.2 International practice - 106

5.6.3 Recommended approach for China - 107

5.7 Facilitate the development of a unified view of smart grids - 109

5.7.1 Background - 109

5.7.2 International practice - 110

5.7.3 Recommended approach for China - 113

References - 114 


\subsection{Define a long-term strategy for the electricity sector and establish an independent and powerful regulator}

\section{Chinese context \\ - China has formulated explicit targets for the short-term future of its electric power system in its $12^{\text {th }}$ Five-Year Plan for Energy Development. However, there are no official goals for the period after 2015. Also, there is as yet no comprehensive vision of China's smart grid, especially with regard to distribu- tion grids and the period after 2020 . \\ - The governance structure of China's energy system regulation comprises a broad variety of ministries and institutions. The multiplicity of these stakeholders as well as the frequent reorganizations that have been taking place lead to difficulties in coordination and increased overlap of competences between the various government institutions involved in the power system regulation. \\ - China's earlier regulatory authority, the State Electricity Regulatory Commission (SERC), was merged with the National Energy Administra- tion (NEA) in 2013. The National Development and Reform Commission (NDRC) and NEA are currently the responsible regulatory institu- tions for the electricity sector. Both share regulatory responsibilities and are subject to political and industrial influence.}

\subsubsection{Background}

Smart grids require strong government leadership Smart grids are not an objective in its own right, but a new approach to meet the challenges that will arise with future electricity systems, for instance with an increasing share of renewable energies. Specifically, smart grids aim at achieving economic efficiency by combining the strengths of conventional grids with the new capabilities of ICT. In Germany, ICT requirements in electricity grids are driven mainly by intermittent supply from RES. Without RES, the conventional grid infrastructure would be sufficient to maintain high reliability levels in Germany's electric power system.

The evolution towards smart grids necessitates strong vision and leadership on the part of the government, because smart grids are not a marketdriven concept:

- A clearly defined long-term strategy for the electric power sector reduces uncertainty for smart grid investors and manufacturers. A lower level of uncertainty on future developments reduces the risks with respect to the investment's future cash flows. As such, smart grid investors and manufacturers are more willing to invest in smart grid technologies. A long-term strategy includes government targets with regard to the development of electricity generation capacities of different technologies (the so-called generation mix) and targets for energy efficiency.

- Clearly defined roles and responsibilities of government bodies are a fundamental requirement for the development of smart grids.

Especially, a clear delineation between the competences of the ministries and the regulator, and possibly other supervisory bodies is associated with a high degree of credibility and assertiveness of government policy.

- An independent and powerful regulator functions as a coordinating institution between all market participants (incumbents and new market entrants). The coordination specifically focuses on the development of equal and non-discriminatory conditions of market entry where all market parties are treated equally and market power of single market actors is limited. The regulator should be sufficiently powerful to impose the measures necessary to manage the development of the electricity sector and the development of smart grids.

\section{Characteristics of an independent regulator There} are two aspects to a regulator's independence:

- independence from the regulated industry and

- independence from politics. 
It is important for the regulator to be independent from the industry that is being regulated. If independence is not guaranteed, the danger of so-called regulatory capture (i.e. the regulator rather favors commercial and industrial interests instead of public interests) is high [1]. On the other hand, a regulator needs to cooperate closely with the industry. Therefore, a relation of mutual trust is important. In some cases, the regulatory office is actually financed by the regulated industry. Note that this is not necessarily a contradiction to the requirement of independence. Following the rules set by the government, the firms are actually obliged to finance the work of the regulator on the basis of a pre-defined payment plan which is not based on a firm's satisfaction with the regulator's work. The risk of regulatory capture is therefore small.

The independence of the regulator from the regulated industry can be ensured in several ways:

- The processes, decisions, and procedures of the regulator have to be transparent so that they can be controlled.

- The regulator should make use of public consultations in which not only the regulated industry but also other stakeholders or the general public can express their views. Again, this avoids opaque agreements between the regulator and regulated industries.

- The regulator should be monitored at regular intervals and should have to justify its work, for example, in an annual report.

- Personal financial interests between the regulator and the regulated industry must be avoided. Two rules are specifically important in this context: first, senior regulator management should not be allowed to have financial stakes in the regulated industry. Second, a moratorium period during which senior regulator management cannot accept a job in the regulated industry is very useful.

Why the regulator should be independent from politics or from the ministry is a less straightforward question. Ultimately, the regulator is a government institution that is governed by the ministry. The relevant concern is the precise legal delineation of authority: who decides on what? In the follow- ing, four main arguments for independence of the regulator are listed:

- Following the classical pattern of the separation of powers, the legislator, the body that sets the rules, needs to be separated from the regulator, who applies the rules, as a system of checks and balances.

- The state may be the owner of the regulated industry, which causes an obvious conflict of interest.

- Ministries are often very close to political decision-makers and base their decisions on criteria that are different from those of regulators. Politicians have to mediate and choose between various diverging preferences in their society. Regulators of a monopoly industry, in contrast, try to improve overall efficiency by applying legal and economic tools.

- Regulation requires a long-term perspective. Grid operators for example, are incentivized to continuously invest in the grid infrastructure only with a high predictability and stability of legal and regulatory decisions. Whereas politicians tend to be subject to so-called short-termism (i. e. they often ignore long-term issues), an independent regulator is less vulnerable to short-termism as he is not elected by the public.

How can independence of the regulator from politics be achieved?

- In the governance structure, the regulator can be an independent chamber of the ministry instead of an integrated department.

- The appointment and especially the dismissal of the chief regulator(s) should be a transparent and well-defined process.

- The regulatory office should have a budget that is largely independent from daily government business.

- The duties and powers of the regulator should be laid down in a law. Specifically, the delineation of competence between the regulator and the ministry should be clearly described. In many countries, a general energy law contains a description of the duties and powers of the regulator. 
- There should be a system of checks and balances. Specifically, it has to be clear who is responsible for regulating and controlling the regulator. For example, this may be a judicial court system, or another regulatory authority with an equal level of substance (e.g. a competition commission). A system of checks and balances allows greater regulator independence.

It is important to note that the precise details of independence from politics or ministries depend strongly on the wider political and governmental structure in a country.

Characteristics of a powerful regulator The need for a powerful regulator is more obvious:

- The competences of the regulator need to be laid down in a law so that decisions can be enforced and challenged in court. In Europe, it has been extensively debated whether the liberalized parts of the energy sector could be regulated under a general competition law or whether sector-specific legislation is necessary to ensure the development of competition. The test of practical experience, for example in Germany, has shown convincingly that sector-specific regulation, executed by a sectorspecific regulator, is necessary (e.g. [2]).

- The regulator needs to have an adequate budget. The stakes in industry are so high that it always pays off for the industry to hire consultants, lawyers, and lobbyists to argue their case; the regulator needs to address these claims. Moreover, good regulation is difficult and requires highly qualified staff; the regulator will have to compete with the industry for qualified employees.

- Electric power companies and other stakeholders should have the right to appeal the regulator's decisions before a court or other tribunals empowered to conduct judicial reviews. Such a system of checks and balances makes the regulator more powerful because knowing that another institution may check and correct the regulator allows him to take more risk.

\subsubsection{International practice}

Long-term strategies for the electric power sector Medium-term to long-term plans with concrete goals regarding electricity consumption, energy efficiency, and/or renewables have been published in many industrialized and emerging countries. These plans often cover a period of at least 25 years (see [3], [4], and [5] for examples from UK, India, and Brazil). In its Federal Energy Concept, Germany has defined binding political goals for renewables until 2050. The government has specified the future share of RES-E in gross electricity production with four goals for different time periods: by 2020 renewables are to have a share of at least $35 \%$ in gross electricity consumption, a $50 \%$ share by $2030,65 \%$ by 2040 and $80 \%$ by 2050 [6]. Similar targets have been defined with respect to gross electricity consumption that is planned to decrease by $50 \%$ until 2050 .

Different studies commissioned by the German government analyze how to achieve the various government targets. At the same time, the scenarios for energy and power sector development put forward in these studies serve as a foundation for policy formulation and a point of reference for further studies on more particular topics such as smart grid development. A study entitled Long-term scenarios and strategies for the expansion of renewable energies in Germany, taking account of developments in Europe and across the world investigated potential scenarios with respect to the development of renewable energies in Germany [7]. The results of this study are used to define strategies for the development of smart grids in Germany (e.g. how to finance the large investment requirements for smart grids).

The role of an independent and powerful regulator The OECD points at the importance of a clear definition of roles and responsibilities with respect to regulation. Within the OECD's recommendations on regulation, the necessity of a common government policy defining clear goals for the regulation process is specified. According to OECD, strategies shall be set for the implementation of these goals to give regulation a clearly defined framework [8]. Furthermore, OECD emphasized the importance of an independent and powerful regulator for the efficient 
development of the electricity sector. The government has the task to clearly define the duties and the power of the regulator [8]. OECD also points out that independence of the regulator is essential since its decisions can have serious economic effects on the regulated parties. This is especially the case for smart grids, where the introduction of competition is directly related to economic effects for the incumbents.

\section{The US American way: FERC}

The Federal Energy Regulatory Commission (FERC) is the regulatory authority in the United States. It is an independent regulator responsible for the regulation of the interstate transmission of electricity, natural gas, and oil. In addition, FERC reviews proposals to build liquefied natural gas (LNG) terminals and interstate natural gas pipelines, and it licenses hydro power projects. Further responsibilities of FERC outlined in the Energy Policy Act of 2005 include, amongst others:

- review of mergers and acquisitions as well as corporate transactions by electricity companies,

- approval of siting and abandonment of interstate natural gas pipelines and storage facilities,

- licensing and inspection of hydro power projects,

- protection of the reliability of the high voltage interstate transmission system through mandatory reliability standards,

- monitoring and investigation of energy markets, and

- administration of accounting and financial reporting regulations and conduction of regulated companies [58].

The independence and power of FERC are specified in 42 USC section $7172 \mathrm{~g}$ - Jurisdiction of the Commission [59]:

"The decision of the Commission involving any function within its jurisdiction, other than action by it on a matter referred to it pursuant to section 7174 of this title, shall be final agency action within the meaning of section 704 of title 5 and shall not be subject to further review by the Secretary or any officer or employee of the Department."
The European Commission (EC) describes the characteristics of a powerful regulator in articles 37 et seq. of Directive 2009/72/EC (see appendix E). It states, for instance, that a powerful regulator should fulfill the following tasks and requirements:

- issue decisions that are binding for electric power companies,

- impose effective, proportionate, and dissuasive penalties on electric power companies,

- ensure high standards of universal and public service,

- protect vulnerable customers,

- contribute to the effectiveness of consumer protection measures, and

- promote effective competition and the proper functioning of the electricity market.

Germany has established BNetzA, a regulator independent from the industry and the government. The powers and duties of BNetzA are recorded in EnWG. Neither the ministry nor the industry can overrule the decisions taken by BNetzA. The regulator's decisions can only be challenged before the court. The German regulator makes use of its power to supervise the network charges of the grid operators, to prevent or remove obstacles in access to energy supply networks for suppliers and consumers, to standardize processes for switching the power retail company, and to improve the conditions for connecting new generators to the grid. Driven by the growing share of renewables and the resulting need to expand the grid infrastructure in Germany, the regulator also has the task of supervising the network expansion process (see - Sect. 4.4.1 for more detailed information on the German regulator).

\subsubsection{Recommended approach for China}

China has not yet formulated explicit targets for the long-term future of its electric power system. This situation risks creating uncertainty among smart grid investors and manufacturers which might consequently postpone smart grid investments. Their uncertainty could be reduced by means of a clearly defined and committed long-term strategy for the electric power sector. Such a strategy should include 
government targets with regard to future generation capacities, shares of different generation technologies (generation mix), and targets for energy efficiency. In Germany, the long-term energy strategy contains binding government goals for a period of roughly 40 years, whereas long-term energy strategies in countries with higher economic growth rates and accordingly more dynamic energy sectors (e.g. India and Brazil) cover periods of approximately 25 years.

The governance structure of China's energy system comprises a broad variety of ministries and institutions. The multiplicity of these stakeholders as well as the frequent reorganizations that have been taking place lead to a rather low degree of coordination and to a rather high degree of overlaps of competence between the various government actors involved in the power system regulation. Based on OECD recommendations and on the German experiences, clearly defined roles and responsibilities concerning the regulation of the electricity sector and the development of smart grids would accelerate and ease the smart grid development in China. The existence of an independent and powerful regulator is by far the most important regulatory issue in this context. China's earlier regulatory authority, SERC, was recently merged with NEA. NDRC and NEA are currently the most relevant regulatory institutions for the electricity sector. As they share regulatory competences and are subject to political and industrial influence, regulation in China is less powerful and independent than in countries such as Germany and the United States. Thus, specific attention should be paid to the development of an independent and powerful regulator in China.

The recommended approach at a glance

- A long-term strategy for the electric power system serves as a basis for more specific smart grid development strategies and objectives and is important for investors to gain investment security.

- It is beneficial to centralize responsibilities for the regulation of the electricity sector in the hands of a single independent and powerful institution (regulator) that supervises the efficient development of the electric power system in general and smart grids in particular.

\subsection{Create level playing fields for access to power system infrastructure and information}

\section{Chinese context}

- Chinese grid operators are still integrated as they own and operate the electric power grids, are responsible for power retail, and invest in RES generation capacities. Also, power system data management (i.e. data collection and provision on grid status as well as generation and consumption quantities) is their task. Both major grid operators are currently developing systems for data management in smart grids. However, these systems focus on information collection by the grid operator for their own operation management, but not on information provision to other market actors.

- New market actors are rarely participating in the development process of smart grids in China. Therefore, the innovation potential which could come from these new stakeholders, for instance from the ICT sector, currently remains untapped.

- The Chinese government plans to establish a modern energy market system to increase competition and affordability. In particular, the reform of state-owned enterprises and the introduction of more market-related elements are envisaged.

\subsubsection{Background}

Benefits of integrating new market actors Smart grids are a relatively new concept aiming at making grid operation more reliable and efficient and accelerating the emergence of new energy-related products and services. Due to the novelty of the smart grid approach, many technological advances and ideas are necessary for smart grids to be developed in an effective and efficient way. Experiences from other sectors and countries suggest that new market actors, i.e. new competitors in the electric 
power sector or companies from other sectors such as the ICT industry, are key drivers of innovations: on the one hand, they offer innovative products and services that were not supplied by established market actors before. In a smart grid context, nonincumbents create new business models and offer new products and services by making use of available power system information and infrastructure in an innovative way (see Sect. 4.4.2 for examples of new market actors in the German electricity sector). On the other hand, new market actors contribute to an increased level of competition which is usually considered to drive innovation, enable greater cost efficiency in production, lower retail price levels, and provide a higher variety of products and services (see $>$ Sect. 2.3).

\section{A fair access to essential facilities is a prerequisite} for new market actor integration New market actors can only enter the markets if equal and nondiscriminatory access to essential facilities (i.e. a level playing field) is guaranteed [9] [10]. In smart grids, level playing fields should be secured in two respects:

- First, equal access to the physical grid infrastructure is important. Since connecting new power generation and consumption units to the power grid is laborious and often associated with high costs, grid operators might have a tendency to discriminate in favor of affiliated companies or against generators and consumers in remote regions. Regulation must prevent such a discriminatory behavior.

- Second, access to power system information and data is required. Power system information and data are getting increasingly important and are a prerequisite for new market actors to offer new and innovative products and services [11]. This does not mean that each established or new market actor has access to all power system information, or that information is even open to the public; instead it means that each eligible market actor has equal and fair access to the information relevant for his business model. This is the task of power system data management, which should be organized in a way that both established and new market actors can participate in the rule-making process and can trust on nondiscriminatory access.

Concepts for a non-discriminatory access to power system information Two concepts should ensure a non-discriminatory access to power system information and data in smart grids:

- Technology neutrality is a regulatory concept for the telecommunications sector that was introduced by the European Commission in Directive 2002/21/EG. In this context, technology neutrality means that the regulator does not impose or discriminate in favor of a particular type of technology. This concept has been applied to several technological issues in Europe, for example with respect to the development of broadband internet, where the regulator left it open to the market to decide between the deployment of different technologies such as digital subscriber line (DSL), power-line communications (PLC), cable modem, or satellite. Technology neutrality is also important for smart grids, e. g. with respect to the question regarding which infrastructure should be used for the power system information exchange. This issue is currently being discussed under the headline of advanced metering infrastructure (AMI). ${ }^{1}$ The development of AMI is in its early introduction phase. Therefore, what specific technology should be used for building up the necessary infrastructure has not yet been settled. Different technologies could be applied, e. g. PLC, wireless, or fiber technologies. In this context, regulation needs to ensure that the most efficient technology will be applied, independently of which company supplies the technology.

- Provider neutrality is another general regulatory concept that is also currently applied in the telecommunications sector in Europe. It basically states that the regulator should ensure that regulation does not discriminate

1 AMI is defined as "systems [that] are comprised of state-ofthe-art electronic/digital hardware and software, which combine interval data measurement with continuously available remote communications. These systems enable measurement of detailed, time-based information and frequent collection and transmittal of such information to various parties." [60]. 
against particular service providers. Applied to smart grids, this means that the regulator should ensure that established and new market actors are treated equally and allowed to offer services on an equal footing in smart grids. On the one hand, services could be provided by established players (e.g. DSO), on the other hand new market actors could provide complementary services or even substitute services of established players for the costumer. Provider neutrality should consequently ensure that competitive advantages (e.g. best technologies or low costs/prices) and not the provider's market power affects consumer's choice.

Defining roles and responsibilities of all market actors eases new market actor integration Liberalized energy markets for energy resources, electricity, capacity, or ancillary services necessitate the exchange of large amounts of information and data between different market actors. A mounting number of market actors leads to a more intensive inter-company exchange of operational and business-related information and data. Against this background, it is of critical importance that all market actors get assigned their respective roles and responsibilities [12]: on the one hand, they have to know the stakes and information requirements of their business partners and other actors in the electric power sector to better understand their business opportunities and their own contribution towards smart grid development. On the other hand, specific rules and data standards for inter-company exchange of business-related information help to reduce the transaction costs among all market actors.

\subsubsection{International practice}

Ensuring technology neutrality For the development of smart grids, the concept of technology neutrality is particularly important with respect to the development of the ICT infrastructure. In principle, different communication technologies could be applied (PLC, 3G, etc.) and different data storages types could be used. Eurelectric, the association of the electricity industry in Europe, has defined basic requirements for the ICT infrastructures in smart grids. The German regulator has addressed this issue as well and specified that, currently, a medium-scale broadband connection should fulfill the necessary requirements to build up the AMI for smart grids. However, the German regulator stresses that with the use of real-time data the quality requirements concerning availability and latency cannot be fulfilled by all existing ICT solutions on the market [13].

Basic requirements for ICT infrastructures in smart grids

According to Eurelectric, the most important requirements for ICT in the context of smart grids are to:

- "Ensure that telecoms infrastructure and links are absolutely reliable, robust, meet operational requirements in terms of speed, capacity and latency and will be available at all times, particularly at times of critical incidents (e.g. be resilient to power outages for several hours because they are needed to rebuild the grid.

- Provide well manageable and robust access control and user privileges mechanisms to the smart grid components and systems.

- Guarantee the confidentiality, integrity and authentication of all smart grid-related communication events.

- Guarantee a robust physical protection for the smart grid components as well as for the whole communication network.

- Ensure that mission-critical telecommunications services are still alive during and up to the end of a wide area 72 hours blackout.

- Implement strong monitoring systems to keep track of all the smart grid activity, implementing Security Information and Event Management (SIEM) systems for security related incidents analysis and maintain well trained security response teams to have a strong and quick response in the case of any security violation.

- Warrant a true real time transfer of information: for a part the smart grid can be seen as an extension of the current SCADA systems; fully available at any time and the guaranteeing the perfect transfer of commands and feedback confirmation of the system operations. 
- Have an end-to-end security approach to guarantee a transversal security layer on the smart grid."

Source: Wording from Eurelectric [61]

Ensuring provider neutrality Provider neutrality is a key requirement for third-party access in general and is currently being discussed within the evaluation of different governance models for power system information management in smart grids. In this context, the European Commission (EC) has been trying to define which actor should be responsible for the data handling in smart grids. The models under discussion are based on unbundled companies or new market actors. The discussion on the different governance models is ongoing and no decision has been taken yet. Three potential models are currently being discussed (for more details see [11]):

- DSO as market facilitator: This model allocates responsibility for power system data management, including collection of data and construction of the necessary information infrastructure to the DSO. The concentration of responsibilities within one institution has the advantage of centralized internal coordination and management of the ICT infrastructure. The main disadvantage of a DSO-centered solution addresses discrimination concerns. In principle, unbundling prescriptions require the neutrality of DSO in Europe. Yet, it is doubtful whether full neutrality can be guaranteed because of asymmetric information to the disadvantage of the regulator. This concept requires significant regulatory oversight. However, it is not new to the regulator, as the DSO are already regulated.

- Independent central data hub (CDH): The $\mathrm{CDH}$ would be responsible for power system data management in smart grids and for central data storage under the supervision of the regulator. A key advantage of this approach is the neutrality of the market facilitator and the non-discriminatory access to information for third parties. The key challenge for this concept is the need to establish coordination mechanisms between the parties involved, e.g. the network owners/system operators and the $\mathrm{CDH}$. It should be noted that the regulator needs to ensure that the provider of the $\mathrm{CDH}$ does not discriminate against other parties or abuse its market power.

- Data access point manager (DAM): The DAM concept focuses on a competitive market for power system information management and proposes to establish independent and unregulated service providers that consumers can choose from. Each DAM offers to build up the necessary information infrastructure for the consumer. Importantly, the DAM does not store the data centrally. Storage remains decentralized with the users, giving consumers full control of their own data. The DAM only acts as an interface which allows each consumer to decide which commercial party gets access to its main data. Such a decentralized approach requires a high degree of standardization to ensure flawless system integration. The DSO would have to control the quality of services provided by the DAM and each regulator would need to define the basic principles of the DAM to integrate them into the national electricity system.

Defining roles and responsibilities of all market actors At the European level, the Smart Grids Task Force (SGTF) of the European Commission broadly defined roles and responsibilities of various market actors in smart grids [12]: in a first step, all relevant smart grid actors (including companies from all supply chain stages of the electric power sector, endusers as well as influencing actors such as regulators, legislation authorities and standardization bodies) have been defined (see appendix E for an overview of all smart grid actors defined). In a second step, current as well as future responsibilities related to the smart grid development have been described for all actors. The work of SGTF should be understood as a practical toolset and guideline for further developments and business models for use by grid operators and grid users [12]. 
Future responsibilities of grid operators in smart grids

"[...] it appears that it is the DSOs who will have to face the biggest challenges so that Smart Grids will become a reality. The reasons include;

- Growing distributed generation, active management of demand, local storage and electric vehicles (EV) will impact the DSO infrastructure. Thus the DSO will have to be an active participant in all such projects along with the actors implementing these projects as these projects will fundamentally change today's relatively static distribution system to a much more dynamic distribution system.

- As more fluctuating distributed generation will feed into the distribution system, gathering and handling the data about the state of the distribution system will be one key issue for the DSO.

- Attention will need to be paid to ensure that all privacy and system security recommendations (in line with the provisions defined by EG2) will be adhered to. Ownership of the data, length of time data is stored etc. will all need to be addressed in an appropriate way.

- The data collected will enable the DSOs to fulfil their duty in relation to the overall grid stability and operational security, given that more and more distributed generation will be connected to the distribution grid.

In order to resolve the above challenges, the DSOs will have to continue upgrading their grid infrastructure, control centres and educating their employees accordingly.

The TSOs will have to provide more support \& communication of data to the DSOs, but will also require more specific information from the DSOs, especially with more distributed generation coming from the distribution grids. In order to achieve this, both TSOs and DSO need to ensure that the standards they implement for communication and data exchange are compatible. It also follows that the TSOs will have to gradually redesign power system control as well as market information management relating to forecasting the overall system load in conjunction with the DSOs.
At the same time, the DSOs will have to strengthen their role in providing the required data relating to the distributed generation, local storage and electric vehicles within the distribution grid. Both TSO and DSO should be able to execute their active role in Smart Grid management by ensuring more sophisticated legal provisions for system security management under increased uncertainty. Following the analysis about funding [...], these mechanisms should include the ability to interfere with the planned market activities in case of disturbed or emergency operational conditions, without "automatic" socialization of the related costs to other grid users.

Finally, the role of grid communications will significantly increase as much more data will have to be gathered and exchanged frequently, which will be in turn used for different purposes by the grid operators and other service providers. As stated above, the standardization of communication protocols as well as clear rules for the handling and the security of this data will have to be developed and enforced. The security of the grid and supply systems as well as the privacy of customer data must remain the top priority."

Source: Wording from Smart Grids Task Force [11]

At the German level, roles and responsibilities of companies in the electric power sector are further specified in EnWG, with an emphasis on specific conditions in Germany. This definition of roles and responsibilities in Germany's most prominent energy law contributed to a high understanding on business opportunities and legal obligations among affected companies in Germany.

With respect to the inter-company exchange of business-related information, BNetzA issued the so-called Business Processes for Delivery of Electricity to Customers (GPKE) based on the United $\mathrm{Na}$ tions Electronic Data Interchange for Administration, Commerce and Transport (UN/EDIFACT) in 2006 (see [14] for more information). GPKE standardize inter-company communication and data exchange in the case of typical business processes such as billing of customers or customers changing their power retail company. In reducing transaction costs of typ- 
ical business processes, GPKE ease the emergence of new market actors.

\subsubsection{Recommended approach for China}

The main electricity sector reform of 2002 mandated the separation (or unbundling) of the state-owned vertically integrated utility responsible for all supply chain stages across China into five big power generation companies, two major grid operators handling transmission, distribution and retail as well as four power service corporations. China's power generation sector can be described as liberalized, as it potentially allows competition between the major five generation companies and the thousands of smaller local and regional generation companies. Chinese grid operators are not completely unbundled as they own and operate the electric power grids, are responsible for retail, and also invest into RES generation capacities. Recently a potential separation of grid operators into transmission and distribution companies or into smaller, regional businesses has been subject of debate [15]. With respect to smart grid developments, non-incumbents (e.g. from the ICT sector) are not yet actively participating in the development process. Therefore, the innovation potential which could come from these new stakeholders, for instance the ICT sector, currently remains untapped.

Experiences from Europe show that defining roles and responsibilities of established and new market actors (including specific rules and data standards for inter-company exchange of businessrelated information) leads to a better understanding of business opportunities and helps to reduce the transaction costs among all market actors. As such, the definition of roles and responsibilities contributed to the emergence of new market actors in the European electricity sector.

Currently, the management of power system data (e.g. grid status information or metering data on electricity generation and consumption) is in the hands of China's grid operators. The concepts of technology and provider neutrality are not applied. As soon as new market actors are to be integrated in the electric power system, power system data management will become more relevant on a broader scale.
The regulator should develop a governance system that will ensure provider and technology neutrality and a level playing field for all stakeholders. Nondiscriminatory access to information in smart grids is of particular importance for third parties to be able to develop their business plans. Neutral information management is therefore a key issue. There are various models currently being discussed in Europe. However, there is not yet one preferred solution fitting all possible contexts. Therefore, recommending a best practice approach to China in this context is not yet advisable. A better approach would be to evaluate what governance model best suits China to ensure non-discriminatory access to information for third parties in the near future.

The recommended approach at a glance

- Defining roles and responsibilities of established and non-established market actors in the smart grid development facilitates the emergence of new market actors and helps to make the exchange of business-related information and data more efficient.

- It should be evaluated which framework for smart grid data management is able to ensure provider and technology neutrality in China. On this basis, a suitable framework needs to be established.

\subsection{Introduce network regulation for efficient investment incentives for electricity grid expansion and upgrade}

\section{Chinese context}

- China's main challenge in the electricity sector is how to handle the massive electricity grid expansion necessary to facilitate the country's rapid economic growth and to integrate the increasing number of RES. A network regulation system that focuses on facilitating investments is lacking. 
- At present, there is no explicit price for power transmission and distribution (network charge) based on actual costs. The source of grid operators' income is the difference between the on-grid and the retail price for electricity, which are both fixed by the government.

\subsubsection{Background}

Network regulation for smart grids Smart grids require substantial investment and innovation, especially from the grid operators. In setting network charges (i.e. prices for power transmission and distribution), regulating institutions have an important influence on the investment behavior of grid operators. Which regulatory scheme (i.e. which specific method used for calculating network charges) is best suited to set incentives for efficient investment is far from settled: in general, regulation should facilitate necessary investment and avoid unnecessary investment at the same time.

In a smart grid context, incentivizing efficient investment into the infrastructure is becoming even more important because benefits of innovation and investment in smart grid technologies may not always accrue to the investor (more information on this issue is presented below). In these cases, additional incentive schemes are required to encourage grid operators to invest specifically in smart grid technologies.

The benefits of regulating only the monopolistic bottlenecks Even if it is far from settled which regulatory scheme is best suited to set incentives for efficient investment, it is generally accepted that network regulation should focus on the monopolistic bottlenecks (transmission and distribution grids), leaving the commercial businesses (generation, trade and retail) to competitive forces and monitoring by competition law [16], [17]. This approach is referred to as disaggregated regulation. Also with respect to the smart grid development, it has been emphasized that regulation should only focus on network charges and network planning while all other aspects should be subject to the market and competition law [13].

Disaggregated regulation has the following advantages:

- Regulation inevitably provides misdirected incentives: only competitive markets are able to provide incentives to hold prices down to marginal costs and to minimize long-run costs. Regulated markets can only do one or the other but not both [18]. In this light, a regulatory focus on the natural monopoly part of the supply chain avoids misdirected incentives at the competitive parts of the supply chain.

- Leaving a stage of the supply chain unregulated eases the market entry of new market actors [19] because requirements for licenses, permits and monitoring obligations in regulated markets raise the investment needed to enter a market.

- A focus on regulation of the natural monopoly may improve the quality of regulation because the regulator's most skilled employees can more easily focus their efforts on the natural monopoly part of the supply chain. It will then be easier for them to get a grip on the regulated firms' cost-developments and investment requirements.

- Different stages of the electric power system may require different types of regulation. In case the regulator decides to regulate the retail stage of the electricity value chain, it is important to set incentives for quality of service and cost efficiency of power retail companies and to allow differentiated tariffs for different consumer groups. Regulation for networks, in turn, needs to set incentives for efficient investment, as network expansion has become so urgent.

Network regulation and investment incentives Disaggregated regulation entails the necessity to apply a specific network regulation scheme. The challenge of network regulation is setting efficient investment incentives (i.e. allowing necessary investment while avoiding unnecessary investment) because the regulator is confronted with the following dilemma: the regulated companies know their own cost structures and market opportunities bet- 
ter than the regulator. As a consequence, regulation cannot provide full-powered incentives to incentivize necessary investment and to avoid unnecessary investment at the same time [18]. Regulators must always accept a trade-off between both goals. ${ }^{2}$ The regulator's challenge is to achieve acceptable levels of both goals at the same time. In accordance with the trade-off described above, two polar cases are commonly distinguished in regulation theory:

- Rate-of-return (also known as cost-passthrough) regulation fixes the rate of return and requires revenues to adjust according to underlying costs. If costs go down, revenues should go down and if costs go up, revenues may go up as well. Therefore, the incentives to reduce costs are low. In fact, firms make profits by inflating the capital base as this is the basis for the rate of return. With cost-pass-through regulation, firms may actually have strong incentives to overinvest (i.e. they do not avoid unnecessary investment).

- Price-cap regulation, also called revenue-cap regulation or RPI-X regulation, tries to avoid these very incentives [20]. Price-cap regulation fixes the price or revenue path ex-ante for the next regulatory period, irrespective of the actual cost development during the regulatory period. If the firm succeeds in reducing its costs more than anticipated by the regulator, the firm can keep the additional profits; this is an incentive to minimize costs. Therefore, this type of regulation is often called incentive regulation. ${ }^{3}$ A counterargument for price-cap regulation is a situation in which costs do not go down, but tend upwards. This typically happens if networks need to be expanded. Under the typical RPI-X regulation, firms then have an incentive to avoid necessary investments [21].

2 Note that the inevitability of this trade-off has been established repeatedly and with great rigor [18]. However, the extent of the regulator's dilemma can be reduced if the regulator has a fair amount of information on the cost structures and market opportunities of the regulated companies.

3 The term incentive regulation is unfortunately somewhat misleading. Regulation always sets incentives: the question is merely what incentives and whether they are good or bad.
The necessity of additional incentive schemes in a smart grid context An additional challenge is starting to emerge given the decentralization of decisions in the smart grid value chain. This challenge can be illustrated through the following example: suppose a new market actor, e.g. the operator of a wind farm, wants to invest in storage capacities close to a wind farm as the facility can store electricity from the wind farm at times of congestion in the grid. Imagine that this investment would be economically more efficient than expanding the distribution grid. From the perspective of the grid operator, only the costs associated with the investment in the grid infrastructure are usually taken into account for calculating the network charges. Thus, the grid operator has no incentive to support the investment in the economically more efficient storage facility. The regulatory framework needs to take account of the spill-over effects and allow costand revenue-sharing models to incentivize investment in smart grid solutions, like the storage facility in the example above.

\subsubsection{International practice}

Regulation of monopolistic bottlenecks and network regulation schemes In Europe and many other countries with liberalized electricity markets, regulation focuses on the natural monopoly part of the supply chain, i.e. power transmission and distribution grids. The other elements of the supply chain, i. e. generation and retail, are liberalized and governed by general competition law only. As such, European power sector regulators focus primarily on the regulation of network charges for transmission and distribution grids. In fact, most of them are not even authorized to intervene in the competitive parts of the electricity sector.

With respect to specific network regulation schemes, the cost-pass-through regulation was traditionally applied in many European countries and the United States. Since this regulation scheme does not set incentives for an efficient grid operation, which is especially important in power systems with a limited need for grid expansion and upgrade, most European countries and some parts of the United States abandoned cost-pass-through regulation in 
favor of different variants of price cap regulation. ${ }^{4}$ Germany for example, applies an RPI-X regulation scheme since 2009 (see $>$ Sect. 4.4.4 for more details). Currently, only Belgium and most parts of the United States [22], [23] still apply cost-pass-through regulation. Owing to the large network investment requirements associated with the transition towards more RES and smart grids, a reform of the RPI-X system to facilitate efficient investment is currently being discussed in Germany and other parts of Europe. In the light of these developments, it can be seen that no single regulatory scheme is preferable in every situation. In the end, regulatory schemes have to take into account the current needs of each country under consideration.

Regulatory approaches setting incentives for efficient investments Network regulation should set incentives for network operators to develop a secure and stable network at the lowest cost. Also, network regulation should set incentives to invest in smart grid solutions, especially in solutions that defer costly investments in grid expansion. Three possible incentive instruments have been applied in countries such as Italy, the United States, and the United Kingdom. These instruments are described below. However, note that this list is not comprehensive:

- Explicit investment incentives could be applied. Such incentives could be so-called rateof-return adders. The idea behind rate-of-return adders is that network operators can earn additional return on equity (ROE) for specific projects selected by the regulator. The rate-ofreturn adder (usually between $2 \%$ and $3 \%$ ) increases the incentive for the network operator to build this specific line or to invest in the respective project. This concept has proven to be successful in Italy. Here, roughly $71 \%$ of all investments made by the Italian TSO Terna in 2009 were priority projects with a rate-ofreturn adder. In Italy, this adder is provided for

4 Even if the general idea behind the price cap regulation scheme is identical in the different countries, specific formula and parameters (e.g. the length of the regulation period or the allowed return of grid operators) differ from country to country. A more specific and detailed overview of network regulation in Europe can be found in [22]. twelve years after the investment [24]. In Italy's case, it can be observed that overall investments, not only those with the rate-of-return adder, increased since the introduction of the adder. Similar effects were observed in the United States [24].

- Explicit profit-sharing mechanisms, or sliding scales, are currently applied in the UK [25]. They can contribute to strengthening the incentives for investment in smart grid technologies. The idea behind the profit-sharing mechanism is that the grid operator is allowed to keep a share of a cost reduction achieved through the application of a smart application (e.g. a storage facility) as a substitute for grid investments. If the costs for the smart application are lower than the investment in the grid infrastructure, but both measures result in a more stable grid, then the grid operator has an incentive to invest in the smart application. Note that the sliding scales have to be granted by the regulator and that calculating their size is a complex task.

- The innovation bonus is an additional instrument motivating the grid operator to invest in smart grid technologies. The innovation bonus is determined by the regulator and grants funds for R\&D activities of the grid operators. The additional costs for the R\&D activity are thereby at least partially refunded to the operator and do not reduce the operator's revenues. The innovation bonus is currently applied in the UK as well and has proved to be an efficient instrument [25]. Similar to rate-of-return adders, innovation bonuses can be designed and granted rather easily by the regulator.

\subsubsection{Recommended approach for China}

China does currently not apply disaggregated regulation, but electricity wholesale and retail prices are subject to regulation. A basic step in the regulatory environment would be to focus on the monopolistic networks alone. This would avoid misdirected incentives at the generation and retail sectors, ease the 
emergence of new market actors, and improve the quality of regulation. In applying a specific regulation scheme, the regulator should focus on setting efficient investment incentives. As there is no regulation scheme suitable to all countries in all contexts, the specific design of a regulation scheme for China has to be elaborated with great rigor. The considerable investment needs in China's electric power grid and the recent experiences with RPI-X regulation in Germany should be taken into account.

China faces the primary challenge of having to increase security of supply. In addition, the potential that comes with smart grids can only be realized if there is an incentive for grid operators to invest into smart solutions (e.g. storage facilities or DSM). Thus, network regulation in China should specifically focus on incentives for security of supply and smart solutions. The application of rate-of-return adders for high priority projects for security of supply and for investment in smart solutions should be evaluated.

The recommended approach at a glance

- Regulating only the natural monopoly part of the electric power sector (transmission and distribution grids) improves the opportunities for market entry of new market actors, reduces misdirected incentives, and may increase quality of regulation.

- Network regulation should focus on setting efficient investment incentives balancing between network expansion and smart grid applications in an economically efficient way. Specifically, the application of rate-of-return adders for projects with a high priority for security of supply might be interesting for China. Furthermore, profitsharing mechanisms or innovation bonuses could be applied to increase the diffusion of innovative technologies in China's electricity sector.

\subsection{Coordinate network expansion planning for electricity grid expansion and upgrade}

\section{Chinese context}

- From 2010 to 2015, generation and grid capacities are planned to increase by roughly $50 \%$ in order to cope with the steadily growing demand. Their further expansion beyond that point in time is inevitable.

- RES generation capacities are expected to increase out of proportion - their share in the electricity mix will increase significantly.

- Electricity grid expansion planning is currently organized in a top-down process with low transparency and little involvement of actors other than government authorities and grid operators.

\subsubsection{Background}

Towards a more decentralized system So far, electric power grids have been designed to transport the electricity generated in central power stations (e.g. coal-fired power plants) to industrial or residential load centers. The subordinated distribution grids have only been used to redistribute the electricity towards end-consumers. Single distribution grids have been operated quite independently from those in other areas. In this setting, a coordination of the necessary grid expansion measures has been important mainly at the level of transmission grids.

The current developments towards more intermittent RES and actively involved end-consumers result in a more decentralized system with bidirectional flows of electricity and information. Massive investments in the power grid infrastructure have to be undertaken to cope with these developments, especially at the distribution grid level: in Germany for example, the investment needs in the distribution grid infrastructure are considerably higher than in the transmission grid infrastructure [21], [26] because roughly $97 \%$ of RES in Germany are connected to the distribution grids [27]. A coordi- 
nation of the necessary grid expansion measures is especially important at the level of distribution grids to facilitate an efficient allocation of investments and reduce economic inefficiencies as much as possible.

Fragmentation of interests Up to now, investments in generation capacities were made mainly by operators of large-scale centralized power plants, a situation that allows grid operators to collect information on where and when a new power plant is planned for construction rather easily. Network expansion planning was a task with a moderate complexity organized by grid operators, operators of large-scale centralized power plants, and coordinating government institutions.

Currently, the number and the heterogeneity of stakeholders with interests in network expansion planning increases:

- Investments into distributed RES are made by a larger number of more heterogeneous companies or even by private investors in many countries [28]. Therefore, advanced planning on how much new grid capacity need to be built in what area becomes more difficult for the network operators.

- The trend towards smart grids is associated with an increasing amount of new market actors with diverse interests. As the business models of new market actors often depend on available grid capacities, their interests are also relevant for long-term electricity network planning alongside the stakes of established market actors making the process of stakeholder consultation more complex. If the interests of stakeholders such as grid operators on different voltage levels, power plant operators, industrial consumers, representatives of small end-users, environmental groups, local governments and central government ministries are not coordinated effectively, network expansion risks being economically inefficient [29].

Against this background, it becomes of vital importance to develop a long-term centrally coordinated NDP that includes plans and interests of all relevant market actors and network users at an early stage.

\subsubsection{International practice}

Network expansion planning in Europe The EU requires each member state to develop a 10 -year NDP currently focusing on transmission grid expansion but not distribution grid expansion [30]. Given the high investment and coordination needs on the distribution grid level, the non-coordination of distribution grid expansion unnecessarily inflates costs of network expansion. In Germany, a group of geographically adjacent DSO consequently started initiatives to coordinate distribution grid expansion planning [31].

The network development plans are based on several scenarios (three scenarios in the case of Germany) concerning the future development of RES and the corresponding electricity system in each member state. The national planning processes are accompanied by 10 -year network development plans of the ENTSO-E. Starting in 2010, these plans are to be issued every two years. The main results of the version published in 2012 are:

- One third of investments planned in the first network development plan of 2010 are experiencing implementation delays owing to long approval processes.

- 52,300 km of extra high voltage transmission lines clustered in 100 projects have to be modernized or constructed, mainly due to bottlenecks related to RES integration.

- 20 megatons $\mathrm{CO}_{2}$ can be saved in the period up to 2022 due to further market integration in Europe.

- Extending the grid by about $1.3 \%$ enables the addition of $3 \%$ more generation capacities [32].

Network expansion planning in Germany In Germany, the rules for developing the national NDP are defined in $\$ 12$ EnWG and the NABEG. • Figure 5.1 illustrates the different steps towards the network development plan in Germany. These are [33]:

- The starting point in the network development process is the scenario framework. It is drafted by the four German TSO and includes forecasts relating to the development of electricity generation, the shares of different generation technologies, and power consumption for the 
Draft Scenario Framework by TSO

Consultation

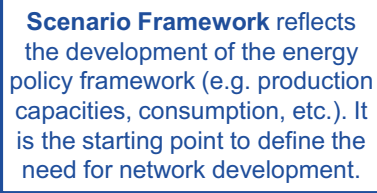

Scenario Framework reflects the development of the energy policy framework (e.g. production capacities, consumption, etc.). It is the starting point to define the need for network development.

\section{Approval of the TSO "Scenario \\ Framework" by BNetzA}

Approved "Scenario Framework"

$\downarrow$

Establishment of the Draft German

Network Development Plan

involving all TSO by June 3, 2012
Federal Requirements Plan
reflects the need to develop the
network in a concrete way

Draft Federal Requirements Plan

by BNetzA

\section{Federal Requirements Plan (Bundesbedarfsplan)}

Fig. 5.1 Process for the network development plan in Germany, adapted from [34]

next ten years. To achieve a realistic forecast, three different scenarios based on different assumptions regarding the increase in generation capacities, RES expansion, and $\mathrm{CO}_{2}$ abatement are considered. The scenarios are submitted to BNetzA, which approves them after a public consultation process. During this process, distribution grid operators and other interested parties have the opportunity to comment on the different scenarios.

- The four TSO subsequently employ the approved scenarios for calculating network expansion requirements. Selecting the necessary expansion measures and assigning a timeframe (two to ten years depending on the respective project) for their realization leads to a first draft of the respective network development plan. BNetzA again assesses this first draft within a public consultation process. During this process, the drafted network development plan is published on a public website and can be commented from various stakeholders and citizens. The network development plan is then revised by the TSO and once again assessed by BNetzA. Furthermore, BNetzA conducts the environmental impact assessment.

- Based on the final version of the network development plan and the environmental impact report published at the same time, BNetzA has the responsibility to draft the so-called Federal Requirements Plan, which is finally brought in the parliamentary legislative procedure.

While this process currently focuses on transmission grids only, it might serve as a best-practice example of how to organize the grid expansion planning on the distribution grid level as well.

The role of stakeholder platforms One of the main goals of BMWi with respect to grid development is to involve new market actors in the strategic smart grid planning process. One prominent example of the ministry's activities is the Future-oriented Energy Grids Platform, which was founded in 2010. In February 2011, the platform was transformed into a permanent dialogue forum [35]. The platform involves all relevant parties of the electricity sector: 


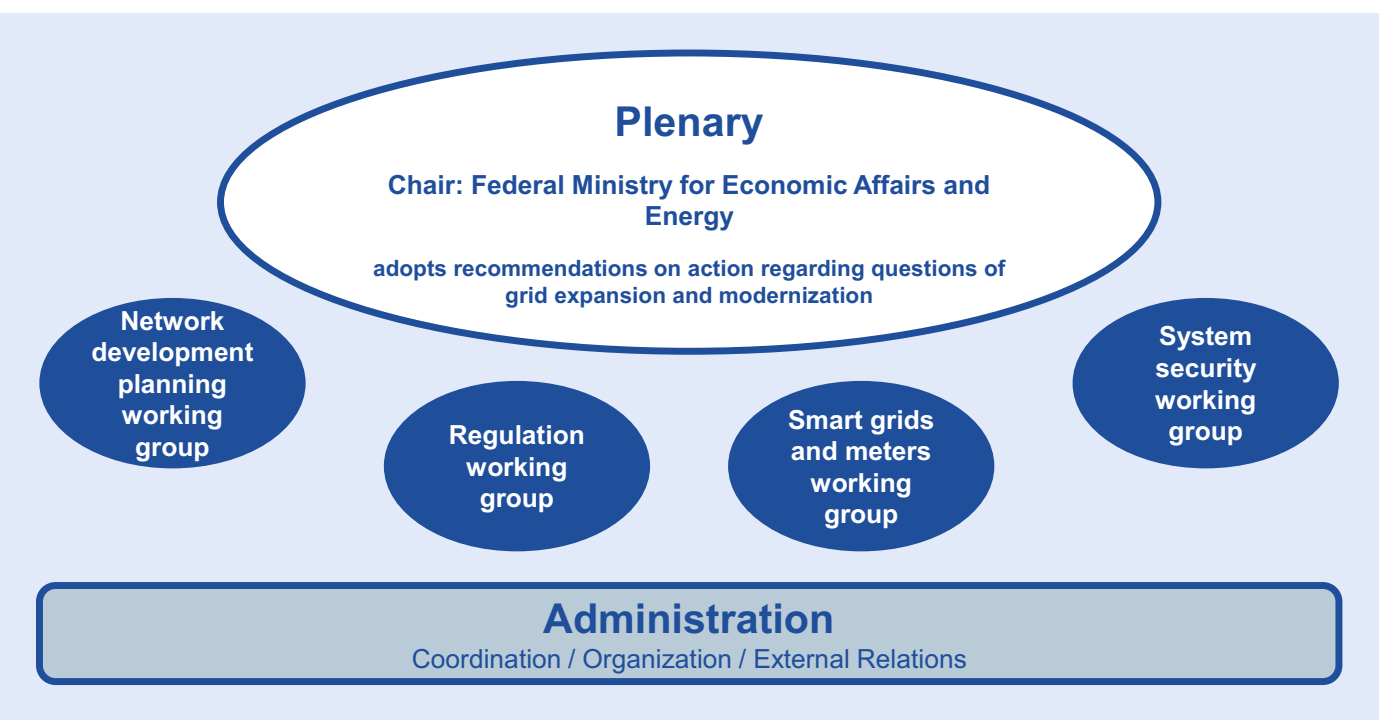

Fig. 5.2 Structure of the Future Oriented Energy Grids Platform, adapted from [35]

grid operators, ICT-companies, environmental and consumer associations, research institutions, and representatives of several ministries and governmental institutions. One of the platform's main tasks is to discuss the draft documents of the network development plan. The platform is therefore an important instrument for the regulator to get feedback on NDP. Besides this task, the grid platform serves as a discussion platform for planning and approval procedures, the regulatory framework for investments into networks, grid connection of offshore wind farms, funding and testing of new technologies, development of smart meters, system stability, and applications of storage systems for network stability.

- Figure 5.2 shows the organizational structure of the platform. The plenary which adopts recommendations on actions is hosted by BMWi. The platform is subdivided in four different working groups, one of them directly responsible for smart grid issues. The different working groups provide consulting services for BMWi or other government institutions, make publicly available the results of their meetings, draft documents and recommendations, and support other publicly funded initiatives for smart grid development. The working group responsible for network development planning for example, proposed a joint grid connection process for offshore wind farms as well as an offshore master plan. In the meantime, both propositions have been included in NABEG [36].

\subsubsection{Recommended approach for China}

China faces a high need to expand the existing electricity network within the next few years. On both levels of the grid, transmission and distribution, this need is driven by growing consumer demand for electricity and the integration of RES. Supporting and guiding the formulation of a consistent and comprehensive concept regarding the set-up of China's future electric power grid is a key task for Chinese energy sector regulation. Government guidance is particularly important in the context of the build-up of RES generation capacities and smart grids both resulting in an increasing number of stakeholders involved in the electric power system.

Today, there are no formalized institutions that acknowledge stakeholder interests in grid expansion planning in China. Therefore, stakeholder involvement currently focuses mainly on the grid operators, the government, and the China Electric Power Planning Institute. Other stakeholders are not integrated into the process in a formal way. 
Three aspects are especially important with respect to the coordination of network expansion in China:

- First, the institution that has the responsibility to supervise the network planning process should be specified. Experience in Germany illustrates that a government institution such as the regulator should take this responsibility. This has the primary advantage that results from the planning process can be transferred directly into the government policy-making process.

- Second, an evaluation should be made of which stakeholders are relevant for network expansion planning. Specifically, formal coordination between grid operators and power generation companies seems to be of great importance to align grid and generation capacity expansion processes. A platform such as the Future Oriented Energy Grids Platform in Germany has been proven effective in integrating new stakeholders in the strategic network development process. The evaluation of which stakeholders are relevant for network expansion planning could also happen within such a stakeholder platform.

- Third, it is beneficial to specify procedures for the development of network plans. In this context, China could take advantage of German experience with the network development planning process. Making mandatory a NDP for both transmission and distribution grids, including smart grids, helps to make network expansion as efficient as possible. Clear scenarios about the development of RES, the general electricity mix, and electricity demand in China are needed as a basis for the definition of a network development plan in China. Such scenarios could then serve as a common basis for the network development process in China. Stakeholder involvement should be a key element of this procedure because the number of stakeholders is likely to increase in the near future due to the importance of non-incumbent market actors for smart grids. These new stakeholders should be integrated into the strategic network development process in a formal way.
The recommended approach at a glance

- A stakeholder platform on the topic of the future electricity network involving all relevant market actors of the electricity sector (e. g. similar to the Future Oriented Energy Grids Platform in Germany) could help to evaluate which stakeholders are relevant for network expansion planning, support the network planning process, enhance mutual understanding among different stakeholders and provide recommendations to the government.

- Make mandatory a network development plan (NDP) for transmission and distribution grids, including a procedure for consulting the NDP with third parties and the public. The NDP should reflect fundamental government policy, future energy policy goals, smart grid goals as well as reliability and security issues. The regulator should supervise and confirm the final NDP, which is then signed into law by the legislature.

\subsection{Improve grid integration of RES}

\section{Chinese context}

- Despite the fact that China has aggressively expanded solar and wind generation capacities since 2006, their shares in the electricity generation mix remain small. However, shares of both generation sources are planned to increase significantly according to government plans. Today, new market actors are only partly involved in the build-up of RES generation capacities.

- Within the existing regulatory framework a lack of sufficient incentives for grid integration of RES persists even though significant improvements have been made in recent years. A considerable number of wind farms is only connected to the electric power grid with delay. 
- Often, wind farms can also not be connected due to the lack of a Low Voltage Ride Through Function. At the same time substantial quantities of wind power still have to be curtailed in order to increase grid stability.

\subsubsection{Background}

New market actors require a physical connection to the power grid In many countries, non-incumbent stakeholders have been investing in RES generation capacities and contributing to the increase of RES in the electricity mix: project developers, industrial and commercial companies, prosumers, and even venture capital and private equity companies [28]. These non-incumbent stakeholders need clearly defined conditions for the physical connection of RES installations to the power grid. Their RES plants need to be technically connected to the grid in such a manner that electricity generated from RES can be fed in. Without an equal and fair access, they abstain from investing in RES. As a result, a huge potential of capital resources for RES investment remains untapped.

The three elements of physical grid integration of RES Grid integration of RES, i. e. the issue of how effective, rapid, and fair the access of RES generation capacities to the electric power grid is organized, consists of three different aspects:

- Grid expansion, necessary due to the connection of RES, is a prerequisite for the large-scale integration of RES (compare $>$ Sects. 5.3 and 5.4).

- Grid connection of RES means technically interconnecting RES to the grid in such a manner that electricity generated from RES can be fed in.

- Specific grid operation issues with large amounts of RES implies assuring that the generated electricity has access to the grid so that it can be transported to end consumers [37].

Grid connection Important issues in many countries are so-called long lead times (e.g. delays).
This subject groups all aspects associated with the time the investor of a renewable energy generation unit has to wait before connecting to the grid and feeding of electricity in the grid is allowed. Long lead times increase the financial risk for investors, creating less favorable credit conditions for them, and thus reducing the incentives for investments in RES.

The effectiveness of grid connection is also affected by how grid connection costs are distributed among the parties involved in the process. In this context, shallow or deep cost approaches can be applied:

- In a deep cost approach, the RES investors requesting connection not only cover the costs of grid connection but also further costs related to grid reinforcement and extension beyond the connection point (i.e. deeper into the network).

- In a shallow cost approach, the RES investor only pays for grid connection costs to the connection point, but not for reinforcement and extension costs. Generally, the deep cost approach creates higher costs and risks for the RES investor. It is therefore more often viewed as an obstacle to RES deployment [37].

Grid operation In countries with a low share of intermittent RES-E in the energy mix, grid operation is usually not adversely affected by RES installations. However, European countries like Germany or Denmark have made the experience that, with a share of approximately $10 \%$ to $20 \%$ of intermittent RES-E, grid operation becomes more and more difficult because regional feed-in often exceeds regional loads and the grids do not have sufficient capacities to absorb and transport the complete surplus of RES-E. One straight-forward remedy for these situations is to expand grid capacities. However, curtailing specific RES generators in times of peak production might be economically more interesting: a study suggests that curtailing only $2 \%$ of the annual electricity production from RES (in times of peak production) could reduce infrastructure investments by $10 \%$ between now and 2030 [26].

Grid curtailment is currently a critical issue in a number of European countries, especially due to the 
lack of specific curtailment rules and compensation issues [37]. Clear and well-defined grid codes for the interconnection of RES on all grid and voltage levels are a decisive factor to ease grid operation with RES [38]. These rules define the interaction of RES and the electric power grid in terms of grid operation. This also includes the handling of congestions and disturbances.

The ICT-integration of RES RES integration issues go beyond the physical connection of RES to the power grid. The basic idea of smart grids is to make all generators and consumers of electricity monitorable and in part remotely controllable by means of ICT. Only if RES plants are remotely controllable, RES generation can be coordinated with grid capacities at any time. In this light, the equipment of RES with communication interfaces is an essential part of smart grids. Also with respect to an economically efficient grid curtailment of RES, the capability of grid operators to monitor and control installations remotely is necessary.

Especially distributed RES (e.g. small rooftop PV installations or single wind turbines) are currently only rarely equipped with technology allowing the grid operator to remotely monitor or control the installations. Given that owners of RES, especially those of small-scale RES, have usually few incentives in investing in communication interfaces, the widespread deployment and usage of such interfaces depends on appropriate regulatory guidance.

\subsubsection{International practice}

The European perspective In its Directive 2001/77/ EC2 [39], the EU laid down a common regulatory basis for the promotion of electricity generated from RES and a framework for the integration of RES into the grid [40]. Paragraphs 1-3 of article 7 contain general references to grid connection and operation issues demanding that $\mathrm{EU}$ member states

D) take the necessary measures to ensure that transmission system operators and DSOs in their territory guarantee the transmission and distribution of electricity produced from renewable energy sources.
Also, the directive proposes priority access to the grid for electricity from RES and favors a costsharing of grid expansion measures between grid operators and RES operators to pure deep cost and pure shallow costs approaches [39].

Published eight years later, Directive 2009/28/ EC3 further regulates grid connection and operation issues. In paragraphs 2-4 of article 16, the EU makes a clear case for priority access for electricity from RES. The Directive recommends that such electricity be fed in with priority, that grid curtailment measures for RES be minimized and justified by the regulator, and that grid expansion costs related to renewable energies be transparent and born in full or in part by the grid operators.

Since 2009, ENTSO-E has been working on a network code for grid connection requirements which aims at

I) setting out clear and objective requirements for generators for grid connection in order to contribute to non-discrimination, effective competition and the efficient functioning of the internal electricity market and to ensure system security [41].

The network code

ע) defines a common set of requirements for power generation facilities, including synchronous generation units, power park modules and offshore generation facilities, to be connected to the network and sets up a common framework for grid connection agreements between grid operators and the power generation facility operators [41].

In defining these requirements, the network code clearly reduces conflicts between RES investors and grid operators and contributes to a better communication between them and to shorter lead times in RES connection as a result of more standardized procedures.

Grid connection of RES in Germany Part 2, chapters 1-3 of the EEG contain regulations that are of critical importance with respect to the effectiveness of grid connection in Germany:

- Chapter 1 section 5 emphasizes that grid operators must immediately and as a priority 
connect all RES to the grid even if this connection necessitates optimizing, boosting, or expanding the grid.

- Paragraph 1 contains a definition of the socalled grid connection point. It is the point in the electricity grid which is at the nearest linear distance from the location of the RES installation. The generation capacity of the RES unit to be connected determines the voltage level of the nearest grid connection point.

- The responsibility of building a connection between the RES installation and the grid connection point is assigned to the grid operator. However, the costs for building this direct connection are passed on to the RES investor as specified in chapter 3 , section 13 , and paragraph 1 of the EEG. Note that due to the rather close meshed electricity grids in Germany, the distances between the installations and the grid connection points are often rather short. Thus, connection costs to be paid by the RES investors are rather low in Germany.

- As specified in chapter 3, section 14, however, the share of the costs within the entire electric power grid that is related to optimizing, boosting, and expanding the grid system is allocated to the grid operator (shallow cost approach). This cost-sharing mechanism prevents the investors in RES projects from installing capacities at great distances from the existing power grid, as they are the ones who have to cover the costs for the direct line to the nearest connection point.

- Chapter 2, section 9 specifies further that the grid operator can only be forced to optimize or expand the electricity grid if this is not economically unreasonable.

\section{EEG - Paragraphs 1-4 of Part 2, Chapter 1,} Section 5

- Grid system operators shall immediately and as a priority connect installations generating electricity from renewable energy sources and from mine gas to that point in their grid system (grid connection point) which is suitable in terms of the voltage and which is at the shortest linear distance from the location of the installation if no other grid system has a technically and economically more favorable grid connection point. [...]

- Installation operators shall be entitled to choose another grid connection point in this grid system or in another grid system which is suitable with regard to the voltage.

- In derogation of subsections (1) and (2) above, the grid system operator shall be entitled to assign the installation a different grid connection point. This shall not apply where the purchase of electricity from the installation concerned would not be guaranteed in accordance with section $8(1)$.

- The obligation to connect the installation to the grid system shall also apply where the purchase of the electricity is only made possible by optimizing, boosting or expanding the grid system in accordance with section 9.

Source: Wording from the BMUB [62]

The combination of a shallow cost approach and an obligation to connect RES with priority is one important factor with regard to grid connection in Germany. Another important element of the EEG (with regard to grid connection) is the definition of what happens if the grid operator fails to connect RES. Part 2, chapter 1, section 10 of the EEG is based on the notion that grid connection rules can be effective only if non-compliance of the grid operator leads to financial losses.

EEG - Paragraphs 1-2 of Part 2, Chapter 1, Section 10

- In the event that the grid system operator violates his obligations under section 9(1), those interested in feeding in electricity may demand compensation for the damage incurred. The liability to pay compensation shall not apply if the grid system operator was not responsible for the violation of the obligation.

- Where there are facts to substantiate the assumption that the grid system operator did 
not fulfill his obligation under section 9(1), installation operators may require the grid system operator to submit information concerning whether and to what extent the grid system operator did not meet his obligation to optimize, boost and expand his grid system. This information may be withheld if it is not necessary in order to establish whether the entitlement in accordance with subsection (1) above exists.

Source: Wording from the BMUB [62]

\section{Grid operation in the presence of RES at the Ger-} man level In spite of the increasing share of electricity from wind and PV power, Germany's electric power grids are still among the most secure and reliable grids worldwide. Germany has made the experience that effective grid curtailment rules are necessary to sustain reliability and security of supply in times of rising feed-in from RES. To allow for an effective grid operation in spite of the presence of RES, the EEG distinguishes between normal and critical grid conditions: ${ }^{5}$

- In normal grid conditions, electricity produced in RES installations has to be fed in at any time - irrespective of electricity consumption. This is regulated in part 2 , chapter 1 , section 8 of the EEG, which states that "[transmission] grid system operators shall immediately and as a priority purchase, transmit and distribute the entire available quantity of electricity from renewable energy sources".

- During critical grid conditions, however, grid operators are allowed to curtail electricity from RES by taking technical control over installations connected to their grid system. Part 2, chapter 2, section 6 of the EEG specifies that all RES plants have to be equipped with a communication interface allowing the grid operator to take over technical control over installations or to limit their effective capacity to $70 \%$ of the installed capacity instead. Those RES with a capacity exceeding $100 \mathrm{~kW}$ have to

5 Critical conditions occur when operational limits, according to common technical guidelines, are violated. be unconditionally enhanced with a communication interface allowing the grid operator to remotely monitor the electricity feed-in in real time and to remotely control installations. To prevent a misuse of grid curtailment, grid operators are obliged to immediately report such measures to the BNetzA. This grid curtailment of RES is not to the detriment of RES investors because they receive equivalent compensations to the extent that they incur no financial losses as a result of the grid curtailment (see appendix E for extracts from EEG, chapter 2, part 2, sections 11 and 12.).

EEG - Paragraphs 1-2 of Part 2, Chapter 1, Section 6

- Installation operators and operators of CHP installations shall provide installations with an installed capacity exceeding 100 kilowatts with technical facilities with which the grid system operator can, at any time:

1. reduce output by remote means in the event of grid overload; and

2. call up the current electricity feed-in at any given point in time.

- Operators of installations generating electricity from solar radiation:

1. with an installed capacity between 30 kilowatts and 100 kilowatts shall fulfil the obligation pursuant to subsection (1) no. 1 above;

2. with a maximum installed capacity of 30 kilowatts shall:

a) fulfil the obligation pursuant to subsection (1) no. 1 above; or

b) limit the maximum effective capacity fed in at the grid connection point with the grid system to 70 percent of the installed capacity.

Source: Wording from the BMUB [62]

Ensuring compliance with the EEG regulation Well specified laws alone might not be sufficient to ensure an effective grid integration of RES if there is no institution with a distinct judiciary function to monitor compliance with the rules 
and settle any dispute between grid operators and power plant owners. In this light, BMUB commissioned and funded the so-called Clearingstelle EEG in 2007. Since then the Clearingstelle EEG serves as a neutral and independent institution with the intention to settle any dispute between grid operators and power plant owners with regard to topics surrounding EEG. The staff of the Clearingstelle EEG consists of an interdisciplinary team of lawyers and engineers with expertise in the field of renewable energies [42].

The general idea is that ordinary courts settle potential disputes rather through costly and time consuming litigation while the Clearingstelle EEG can offer alternative dispute resolution options such as

- mediation,

- joint dispute resolution, and

- arbitration [42].

In addition, the Clearingstelle EEG reports the results of past legal disputes such that a high transparency on the jurisdiction exists among grid operators and plant owners. In sum, the Clearingstelle EEG clearly contributes to a high compliance with the EEG regulation in Germany. ${ }^{6}$

\subsubsection{Recommended approach for China}

The physical grid integration of RES in China currently lacks efficiency. This refers to both grid connection and grid operation. Specifically, a considerable part of wind power is currently being curtailed. There is also evidence that only a very small part of investments are being made by non-incumbent players in China: investments from venture capital and private equity companies for example, are quite low compared to many other countries [28]. For the government's ambitious RES expansion targets to be achieved and in order to incentivize new market actors to invest in RES, the physical grid integration of RES has to become more effective.

6 Further information on the work of the Clearingstelle EEG can be found at $\boldsymbol{r}$ https://www.clearingstelle-eeg.de/ english.
Transparency and a clear division of responsibilities between grid operators and RES investors would encourage the deployment of RES and incentivize new market actors to invest in RES. The following recommendations are made based on best practices from Europe and especially Germany:

- The grid operator is a monopolistic company with special responsibility. He has to define clear, transparent, and technically sound grid codes for the integration of generation units at all voltage levels. These codes have to be defined properly and made binding.

- For an efficient and fast connection, grid connection points have to be defined properly for all kinds of RES on all voltage levels of the grid. RES need to be assigned a grid connection point on request, so that the interconnection point can be installed without delay and according to well-defined technical standards.

- Grid operators have to bear liability for the grid connection of RES. This is very important, because liability puts a high priority on the establishment of the grid connection and avoids delays on the grid operator's side. In this context, definition of financial incentives (e.g. in form of penalties) is an effective measure to quicken the grid connection process and to reduce the risk for RES investors.

The same arguments which hold for the grid connection are equally valid for grid operation issues. To ensure grid stability, it is necessary to curtail RES in times of critical grid conditions. To provide transparent procedures to the RES operators, detailed processes for curtailment of RES (including documentation, transparency rules, timeframes, involved parties, etc.) have to be defined and the requirements for information exchange within these measures have to be specified. To ensure an economically efficient grid curtailment, the installation of communication interfaces at RES installations should be promoted by appropriate regulation (such as part 2, chapter 1, section 6 of EEG in Germany). Moreover, it is important that grid curtailment of RES only takes place if this is urgently needed to stabilize grid operation and that the compensation to the RES investor is calculated transparently. 
The experiences from Germany further show that the establishment of an independent institution offering mediation, joint dispute resolution, and arbitration services contributes to a high compliance with the regulation.

The recommended approach at a glance

- Grid connection points and binding grid codes specifying respective responsibilities of grid operators and power generators have to be defined.

- Grid operators have to bear liability regarding the grid connection of RES.

- Binding procedures for curtailment of RES have to be defined. To ensure an economically efficient grid curtailment, the installation of communication interfaces at RES installations should be promoted by appropriate regulation.

- An institution offering mediation, joint dispute resolution, and arbitration services in the context of grid connection issues should be assigned.

\subsection{Optimize the balancing of electricity generation and consumption}

\section{Chinese context}

- Due to the high share of industrial load, China's overall electricity load curve is currently rather flat. In the future, China's electricity generation might become considerably more fluctuating owing to the further buildup of RES generation capacities planned by the government. In addition, shares of more intermittent residential and commercial electricity consumption are expected to increase. Both factors will lead to regionally higher load variability in China.

- Higher load variability necessitates a more effective coordination of electricity generation and consumption. Specifically, with growing shares of intermittent RES it will become indispensable that electricity consumption will be, at least partly, able to follow electricity generation. This necessitates the use of economic incentives as well as sophisticated technologies facilitating the coordination of electricity generation and consumption. All types of consumers, i.e. industrial, commercial, and residential, have to be involved in these activities.

- Time-of-use pricing (i.e. electricity prices depending on the time when electricity is provided) aims at incentivizing electricity consumers to shift their consumption according to generation and grid capacities. It has gradually been introduced in China to all categories of users except residential consumers and irrigational users. The Chinese government recently announced that it would introduce time-of-use pricing also for residential consumers by the end of 2015 . While this is certainly a step in the right direction, it is still questionable whether the present tariff system offers sufficient price incentives for a pronounced intraday shifting of power demand.

\subsubsection{Background}

Peak shaving and residual peak load shaving The balancing of generation and consumption of electricity is of crucial importance for the stable operation of electric power systems. In a power system with $100 \%$ generation from large central (bulk) power plants, electricity generation follows the load. Sometimes, peak loads may cause shortages on the generation side. Peak shaving, i. e. reducing the electrical power consumption during periods of maximum electricity demand, is then an important factor to stabilize system operation. In power systems with a high share of RES, however, the motivation for peak shaving changes somewhat: in such power systems, the residual load, i. e. the difference between load and renewable generation, is highly volatile due 
to the intermittent nature of renewable generation. In these cases, large central power plants, usually conventional fossil fuel-driven power plants, have to cover the residual load - also known as residual peak load shaving (or residual load balancing).

Balancing mechanisms and technologies like demand side management (DSM), supply side management (SSM), microgrids, virtual power plants (VPP), and energy storage can be employed to facilitate the coordination of electricity generation and consumption. All these mechanisms and technologies require an ICT infrastructure for measurement, control, and billing of various loads and/or generation units at local, regional, or distributed sites.

Demand side management DSM is an important mechanism for peak shaving and residual peak shaving for different types of loads. DSM means incentivizing electricity consumers to adapt their consumption to the availability of electricity generation. Principally, the loads can be influenced by means of two different mechanisms: on the one hand, end customers can react manually to suitable incentives such as price signals. On the other hand, automated load control is conceivable for devices where deferred use and a modulated operation mode entail no loss of comfort, economic consequences, or other restrictions in everyday household/business life (dispensable loads). With respect to the potential of DSM on low voltage level, the necessary IT infrastructure and the relation between DSM and AMI have been discussed widely [43].

Supply side management Supply side management (SSM) works similarly to DSM but refers to local or distributed generation facilities. SSM means incentivizing electricity producers to adapt their generation to the demand of electricity. The generation units are typically small-scale residential units like $\mathrm{CHP}$ plants or larger $\mathrm{CHP}$ units located at industrial facilities.

Virtual power plants Virtual power plants (VPP) aggregate power generation, storage, or consumption units into one balancing unit by means of ICT metering and control technologies. These units may be spread out over the grid and belong to separate owners. VPP are especially useful in the context of electricity markets: the VPP operator controls or manages the operation of the generation units to follow a joint schedule or to offer balancing power to the system operators.

Microgrids Microgrids are a specific solution to manage the intermittent character of RES on a regional level. They are grid areas in which generation from local RES or other distributed generation and consumption is balanced by local control mechanisms by means of information exchange between the devices through local ICT. As such, the higherlevel distribution grid to which the microgrid is connected is not necessarily and immediately exposed to the intermittence of RES connected to the microgrid. Island grids without any connections to distribution grids are an extreme form of this approach. Note that microgrids are geographically connected grid regions, while VPP are virtually aggregated units which are distributed throughout larger grid areas.

Energy storage Requirements for power storage differ according to field of application. Some storage technologies are used to balance fluctuations within a very short timeframe (e.g. some milliseconds) and others are used for longer timeframes (e.g. days or weeks):

- Hydrogen generated by means of electrolysis can be used to store electric power for timeframes lasting up to several months.

- Pumped-storage and compressed air energy storage power stations are suitable for an intraday balancing of generation and consumption. On a global level, pumped-storage power plants are the most important technology to store electric power.

- Electrochemical storage mediums like batteries are employed to store electricity for timeframes ranging from one hour to several days.

- Centrifugal mass storage, super caps, and superconductive inductors can be charged and unloaded within an extremely short timeframe. They are used for grid stabilization services and voltage maintenance [44].

Barriers to the development of balancing mechanisms and technologies There are many different 
barriers to the development of balancing mechanisms and technologies as described above. The elimination of such barriers calls for suitable regulatory measures. In principal, these barriers can be classified into three different categories [45]:

- Technological barriers refer to the fact that the maturity of some technologies that might be important for the balancing of generation and consumption is still rather low [46]. Electrochemical storage mediums such as batteries, for example, are in many cases still too expensive to be used in a widespread manner [44].

- Economic barriers exist, because for many stakeholders in the electricity sector the costs of investing in balancing mechanisms and technologies are still higher than the benefits. For potential investors, especially for smallsized third parties, the administrative overhead and the necessary investments in ICT for controlling, balancing, and billing are relatively high. Many of them consequently refrain from investing in balancing technologies. Specifically, there are many open questions related to billing, balancing, and accounting, in the case that several market actors coordinate power generation and load for different business purposes.

- Institutional barriers may arise if new technologies have to adapt to practices and codes developed in a context in which these new technologies were not yet known. For example, microgrids require specific connection codes that are different from small conventional distribution grids. The costs of deploying such balancing mechanisms and technologies critically depend on connection codes, legal reporting obligations, and application processes [45].

\subsubsection{International practice}

Reducing technological barriers In order to promote the development of technologies and business models to balance electricity generation and consumption, government-supported R\&D programs are of fundamental importance (Germany's $R \& D$ program E-Energy is presented in Sect. 4.4.6).
Many countries have established funding schemes to reduce existing technological barriers:

- The United States for example, claim to invest at least $\$ 3$ billion into smart grid projects [47]. Specifically, they have funded two important R\&D programs for microgrid and DSM demonstration projects run by the United States Department of Defense (USDOD) and the United States Department of Energy (USDOE). The USDOD provided $\$ 38.5$ million for three different military base microgrid demonstrations, with a focus on reliability and energy security [45]. The USDOE spent over $\$ 50$ million for nine projects having the concrete goal of achieving a $15 \%$ peak load reduction in the local distribution feeder [45].

- In recent years, the EU has also invested significant amounts in smart grid-related $R \& D$ and devoted several major research efforts exclusively to DSM, SSM, VPP, microgrids, and energy storage. One promising example is the Future Internet for Smart Energy (FINSENY) project which was conducted as part of the private public partnership Future Internet from 2010 to 2013 . $^{7}$

In the United States and in Europe, the experience was made that two factors are especially important with respect to the success of $R \& D$ funding (cf. e.g. [45]):

- Clear targets on what should be achieved by means of the research program have to be defined in advance by the funding organization. Only if such targets exist can the success of the research project be measured and controlled during and after the project.

- The recipient of $\mathrm{R} \& \mathrm{D}$ subsidies often has to co-finance the research program with its own capital. Financial participation is an important additional incentive to ensure that the recipient of the subsidies will efficiently and effectively carry out the research project.

Reducing economic barriers All regulatory approaches aiming at decreasing investment costs in

7 See http://www.fi-ppp-finseny.eu for more information on this project. 
balancing mechanisms or technologies or increasing profits related to their usage can be seen as an effective measure to promote their development:

- A possible solution aiming at reducing investment costs is to directly subsidize the usage of balancing mechanisms or technologies. To promote electricity storage, for example, the German government recently established a co-funding scheme for electric battery storages newly installed in private houses in combination with PV. The purpose of this measure is to promote local consumption of electricity generated by PV, thereby limiting the PV feedin to the distribution grid.

- Time-of-use pricing is an important option to increase profits related to the usage of DSM, SSM, and energy storage. The higher the price differences between peak and base load prices, the higher the rate of return of DSM, SSM, and energy storage.

- The attractiveness of microgrids critically depends on the difference of electricity generation costs within the microgrid and general retail prices for electricity. If a microgrid is able to produce its own electricity, consumers within the microgrid are independent from general electricity retail prices. However, it is only if general retail prices for electricity are higher than electricity generation costs within the microgrid that investments in these technologies might be potentially amortized after some years. In this light, increasing electricity retail tariffs can be seen as an important driver for investments in microgrids. Depending on the regulatory environment, microgrid operators might also be able to export the electricity to the distribution grid. In this case, the question to be asked is whether the operators receive payments for the electricity they export and what rate these payments depend on: wholesale, retail, or potentially a feed-in tariff. Feed-in tariffs that are higher than the general retail price for electricity and higher than electricity generation costs inside the microgrid can be seen as an effective measure to promote the development of microgrids [48].
Reducing institutional barriers Standards for regulating the general grid connection of RES are common in most countries. Like Europe, the United States, for example, have a standard for grid connection: IEEE 1547 was established in 2003. These standards often do not contain specific rules for VPP or microgrids. However, some countries have started to issue special regulation for VPP and/or microgrids:

- To ease the grid connection of microgrids, the United States issued IEEE 1547.4: Guide for Design, Operation, and Integration of Distributed Resource Island Systems with Electric Power Systems. This standard presents alternative approaches and good practices for the design and operation of microgrids and their integration with distribution grids. For instance, this includes the ability to separate from and reconnect to the distribution grid while providing power to the islanded microgrid. The IEEE 1547.4 standard is currently gaining approval on the international level.

- Another example of institutional barriers for microgrids being reduced is Germany, where microgrid operators have been relieved of several legal requirements that have applied to distribution grid operators in Germany since 2005. Special rules applying to so-called site networks have been introduced by EnWG for grids covering campuses and enterprises. Such site networks can be designed as microgrids. For example, operators of site networks are not subject to the general connection obligation ( $\$ 18$ EnWG): they are permitted to publish less reports on grid conditions ( $\$ 14 \mathrm{~b}$ EnWG), have less monitoring obligations ( $\$ 35$ EnWG), and less obligations to report service disruptions ( $\$ 52$ EnWG).

\subsubsection{Recommended approach for China}

The key driver for the usage of balancing mechanisms and technologies in China is peak shaving due to the high growth rate of power consumption. The balancing mechanisms and technologies described above, especially DSM and energy storage, 
will contribute to a more effective peak shaving and to an improved utilization rate of the grid infrastructure. In the long term, residual peak shaving - necessary due to the increasing expansion of RES generation capacities - will be an additional aspect in China. Balancing mechanisms and technologies like SSM, VPP, and microgrids will become more important in this context.

In 2011 , more than $70 \%$ of China's electricity was consumed by the industrial sector [49]. In general, the technical potential for peak shaving in this sector is comparatively high and can be realized with dedicated ICT solutions. Usually, the potential for peak shaving is smaller and more distributed in the commercial sector and especially in the residential sector. ICT requirements and costs of implementing balancing mechanisms and technologies in these sectors are therefore comparatively higher. In this light, balancing between generation and consumption in China should be optimized with a focus on industrial and commercial consumers in the short- to mediumterm and on residential consumers in the long term.

With this general background in mind, several specific policies may foster the development and usage of specific balancing mechanisms and technologies:

\section{- Time-of-use pricing to incentivize the usage of} DSM and energy storage: Time-of-use pricing has gradually been introduced to all categories of users except residential consumers and irrigational users. With regard to commercial and industrial consumers, China already has a very high time-of-use adoption rate, with roughly two thirds of large-scale customers using time-based electricity tariffs [50]. Even if the difference between peak and off-peak prices has increased in recent times, it is still questionable whether the current tariff system offers sufficient incentives for a pronounced intraday shifting of power demand [51]. The Chinese government recently announced that it would also introduce time-of-use pricing for residential consumers by the end of 2015 [50]. In designing this new tariff system, sufficient differences between peak and off-peak prices have to be considered as a key success factor. The same key success factor applies to time-ofuse pricing in non-residential sectors.
- Additional R\&D funds for SSM, VPP, microgrid, and energy storage demonstration projects:

To help abolish technological barriers, the Chinese government has decided to promote the development of different balancing mechanisms and technologies and it has already started to foster R\&D in these areas. From an institutional point of view, the NEA has played the most active role in promoting balancing mechanisms [45]. Other institutions that are interested in the promotion of such technologies are the NDRC, the Ministry of Housing and Urban Rural Development, and the MOF [45]. However, the pertinent research has just started in China and consequently needs to be intensified in the future to catch up with international best practice technologies. Thus, additional R\&D funds should be set up for SSM, VPP, microgrid, or energy storage demonstration projects. In this context, it is specifically important to set up concrete performance targets for funded demonstration projects and require a co-financing of the subsidies' recipients.

\section{- Feed-in tariffs and interconnection standards} for microgrids: compared to European countries and many other countries, retail prices for electricity are very low in China. As a consequence, prices for locally generated electricity (e.g. in microgrids) are often significantly higher than local retail prices for electricity. This has already led individual investors to abandon microgrids demonstration projects [46]. However, increasing electricity retail prices to promote the development of microgrids would directly contrast one of China's primary energy policy goals: affordable retail prices. Therefore, feed-in tariffs for local RES or microgrids could be an option to incentivize investments in microgrids. Also, interconnection standards for microgrids (such as IEEE 1547.4), currently not existing in China, should be issued and made legally binding. 
The recommended approach at a glance

- Coordination between generation and consumption should be optimized with a focus on industrial and commercial consumers in the short- to medium-term and on residential consumers in the long term.

- Peak shaving is of crucial importance in the short to medium term. To promote peak shaving, it is specifically recommended to refine time-of-use pricing in China in order to set sufficient incentives (by means of high differences between peak and off-peak prices) for investments in DSM and energy storage for all categories of consumers.

- Residual peak shaving is relevant in the long term. Additional R\&D funds for SSM, VPP, and microgrids as well as interconnection standards and feed-in tariffs specifically for microgrids can be employed to reduce technological, economic, and institutional barriers to the development of SSM, VPP, and microgrids.

\subsection{Facilitate the development of a unified view of smart grids}

\section{Chinese context}

- Due to the different strategies of China's grid operators with regard to smart grid development and the fact that the Chinese government has not yet publicly defined its view on smart grids, there is still no unanimously accepted vision on the technological and organizational design of smart grids in China. As a result, there is much uncertainty among potential smart grid investors regarding the future development.

- The diversity of stakeholders interested in standardization in China has increased in recent years: in addition to the central government, research institutes, universities, civilian and defense industries, and regional governments, all have their own interests with regard to standardization and are increasingly willing to contribute to the standardization process [63].

\subsubsection{Background}

Smart grids require a common understanding of all stakeholders Smart grids represent a concept aiming at the integration of information and communication among market actors from various sectors as well as a multitude of power system components. In a smart grid, data on the grid status is exchanged as well as data related to services, products, and reporting obligations. A key challenge of smart grids is to integrate its different components and ensure that they can communicate with the help of ICT. The definition of common standards for interfaces and communication protocols is therefore of utmost importance in order to ensure interoperability and a smooth exchange of information between the different elements of a smart grid. The costs of connecting smart grid technologies through ICT (integration costs) significantly affect the overall costs of deploying smart grid technologies and are thus one key success factor for smart grids. A prerequisite for reducing integration costs is a unified view on smart grid technologies, business processes, and procedures. Furthermore, smart gridrelated technologies, products, and services can only be developed by the variety of stakeholders in a costefficient manner if requirements for smart grid solutions are accepted by all smart grid stakeholders.

\section{Standardization as a means to create a common} understanding Standardization can serve to create a common understanding between participating stakeholders, thus increasing interoperability, and reducing smart grid integration costs. According to the German Institute for Standardization (DIN), standardization usually has at least five major goals:

- securing the competiveness of domestic industries in the international context of a broad ensemble of diverging technologies and procedures, 
- providing a strategic instrument to foster economic and social success,

- supporting and relieving government regulation,

- fostering technological convergence, and

- creating efficient processes and instruments [52].

These goals illustrate that the current scope of standardization goes well beyond the integration of two or more individual systems. The following aspects should be focused on in the context of smart gridrelated standardization issues:

- How can the development of standards support the common understanding of future smart grids?

- How can the process of national and international standardization be optimized for faster time to markets of necessary standards?

- How can the heterogeneous requirements and viewpoints of different stakeholders with regard to smart grid architecture be expressed?

The government's role in promoting standardization In some cases, governments are quite actively involved in standardization processes. By issuing laws and regulations providing minimum standards for certain goods, services, or technologies, governments are even able to legally enforce standards. In many cases, however, standardization is mainly pushed forward by the private industry in cooperation with accredited standards developing organizations (SDO). ${ }^{8}$ Note that, due to the involvement of many different stakeholders in SDO, a high level of coordination between the various stakeholders is necessary.

Even if standardization is left to the private sector, many governments acknowledge its importance in today's quickly developing technological environment. In 2009, for instance, the German government issued a Standardization Policy Concept of the Federal Government [53]. This policy paper presents the goals and expectations of the government with regard to standardization as well as specific measures

8 Especially in those areas where potential harm to citizens resulting from non-compliance with the standard is low, standardization is mainly left to private industry [64]. of different ministries. In general, governments have many options to influence standardization, and consequently they play an important role in this context. To give just a few examples, possible governmental measures to promote standardization are:

- hosting conferences and symposia on standardization issues,

- strengthening the role and (financial) power of SDO,

- actively participating in the work of SDO, and

- considering standardization issues in the educational system [53].

\subsubsection{International practice}

European Mandate M/490 The EU specifically acknowledges the importance of standardization in smart grids: the European Commission issued the European Mandate M/490 with the intention to promote the development of a unified and commonly accepted view on smart grids to increase interoperability and reduce integration costs. To execute Mandate M/490, the Smart Grid Coordination Group (SG-CG) was founded by the major European standardization organizations European Committee for Standardization (CEN), European Committee for Electrotechnical Organization (CENELEC), and European Telecommunications Standards Institute (ETSI). All of them are mirror-organizations of the main international standardization organizations International Organization for Standardization (ISO), International Electrotechnical Commission (IEC), and International Telecommunication Union (ITU).

Scope and objective of Mandate M/490 "The challenge of Smart Grids deployment will require changes to existing standards, industry rules and processes.

This mandate is to address such a challenge in the field of standardization. The expected long term duration of Smart Grid deployment suggests the need for a framework that is:

- Comprehensive and integrated enough to embrace the whole variety of Smart Grid actors and ensure communications between them 


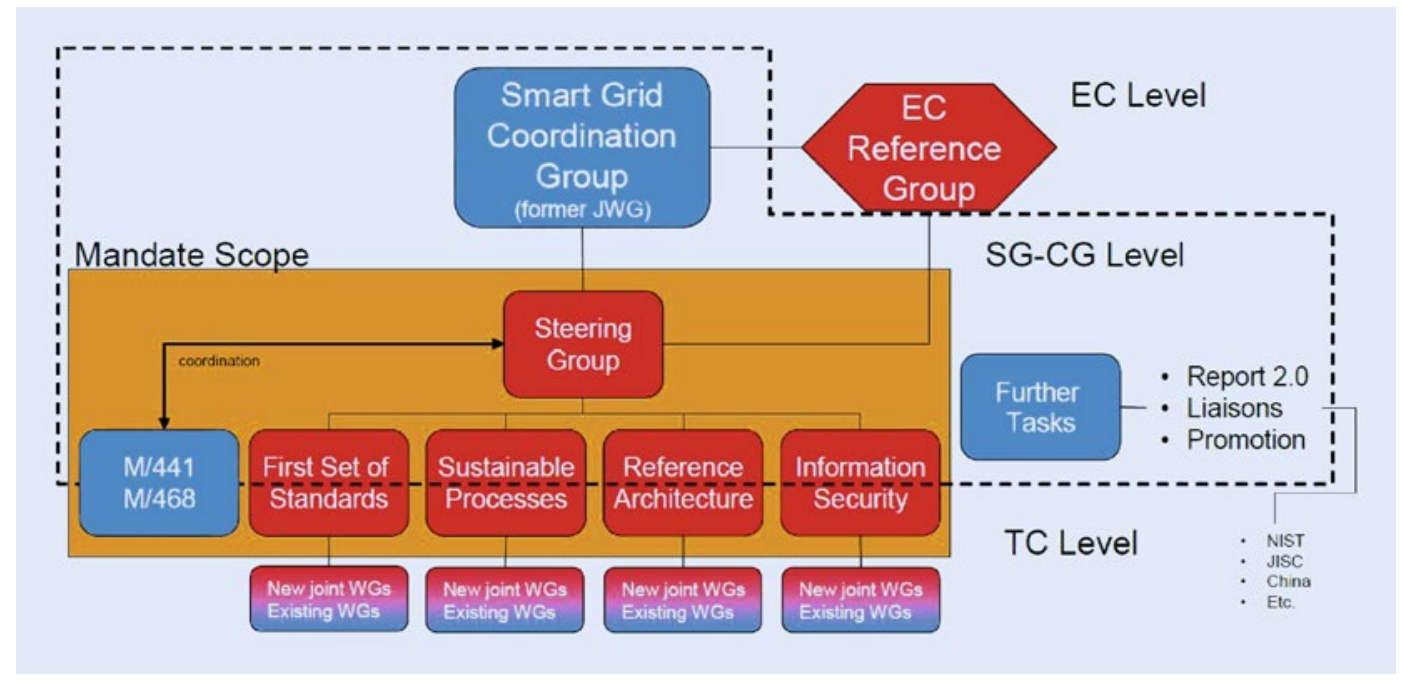

- Fig. 5.3 Organizational structure of M/490 SG-CG, taken from [55]

- In-depth enough to guarantee interoperability of Smart Grids from basic connectivity to complex distributed business applications, including a unified set of definitions so that all Members States have a common understanding of the various components of the Smart Grid.

- Flexible and fast enough to take advantage of the existing telecommunications infrastructure and services as well as the emergence of new technologies while enhancing competitiveness of the markets.

- Flexible enough to accommodate some differences between EU Member States approaches to Smart Grids deployment [...].

The expected framework will consist of the following deliverables:

- A technical reference architecture, which will represent the functional information data flows between the main domains and integrate many systems and subsystems architectures.

- A set of consistent standards, which will support the information exchange (communication protocols and data models) and the integration of all users into the electric system operation.
- Sustainable standardization processes and collaborative tools to enable stakeholder interactions, to improve the two above and adapt them to new requirements based on gap analysis, while ensuring the fit to high level system constraints such as interoperability, security, and privacy, etc."

Source: Wording from the European Commission [65]

Organizational aspects of Mandate M/490 The SG-CG consists of four working groups that are synchronized with those of mandates M/441 (smart metering) and M/468 (electric mobility). The following four working groups are organized under a joint steering committee (see • Fig. 5.3):

- First Set of Standards (WG FSS): Responsible for compiling a consistent set of smart grid standards based on existing standards by applying the concepts and processes from the other working groups.

- Reference Architecture (WG RA): Responsible for the design of a technical reference architecture to be used in the other groups in order to consistently and comprehensively describe smart grids. The technical reference architecture can be thought of as a map showing the 


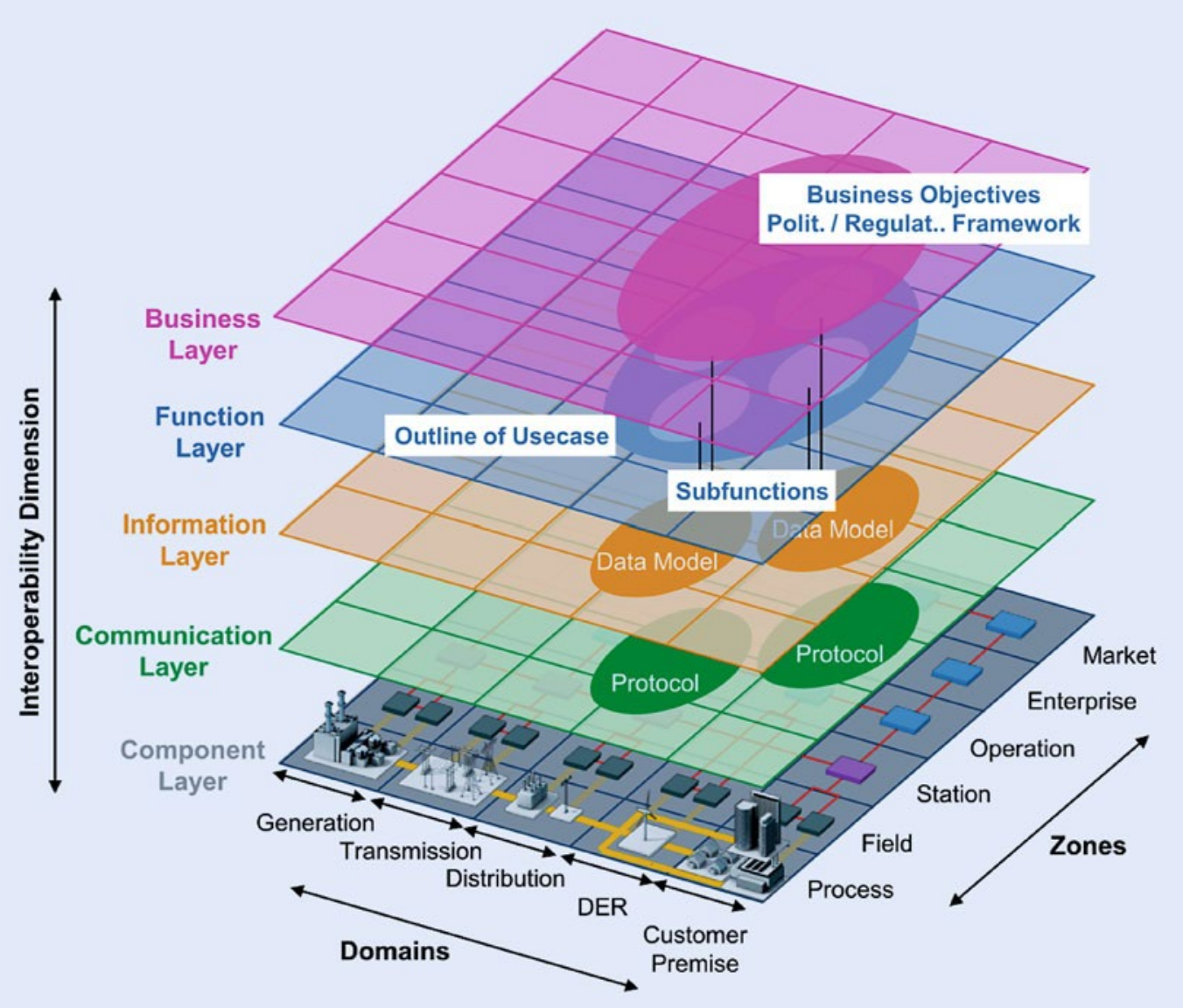

- Fig. 5.4 SGAM - The Smart Grid Architecture Model, taken from [56]

boundaries as well as different areas of smart grids. It can be used to increase the understanding of who does what with whom in which manner in smart grids.

- Sustainable Processes (WG SP): Responsible for the design of processes for the identification and application of smart grid use cases. In the smart grid context, use cases describe specific smart grid applications and define the important actors, systems and technologies and their requirements and functions contributing to the development of a common understanding of smart grids [54]. Use cases are neutral with regard to specific projects, products, and vendors and can also be applied within a gap analysis revealing the need for future smart grid standardization.
- Smart Grid Information Security (WG SGIS): Responsible for identifying the guidelines to achieve information security and privacy in the context of the application of current smart grid standards.

Main results of European Mandate M/490 As it provides the structure referenced in the results of the other SG-CG working groups, the so-called Smart Grid Architecture Model (SGAM), a technical reference architecture developed within WG RA, can be described as the first deliverable of the Mandate M/490. SGAM (see - Fig. 5.4) is a threedimensional model of the European smart grid environment. It distinguishes between physical domains (generation, transmission, distribution, distributed energy resources, and customer premises), 
management zones (process, field, station, operation, enterprise, and market) and interoperability dimensions (component, communication, information, function, business).

The different interoperability dimensions are based on the GridWise Architecture Council's (GWAC) Inter-operability Context-Setting Framework [57]: the component layer represents the physical/technical aspect of the system and is therefore used to model physical equipment and infrastructure. The communication layer further specifies protocols and procedures of data exchanges between the components, while the information layer outlines the information models used in the context of the components and information exchange. Above these solution-oriented dimensions, the function layer specifies the logical and thus technology-independent viewpoint in terms of the functions and services realized by the implementation, while the business layer finally represents the objectives as well as regulatory and legal requirements connected to these functions.

WG SP applied the SGAM to identify smart grid use cases. The use case methodology is widely based on the Publicly Available Specification (PAS) IEC 62559 and includes a template for the unified description of use cases as well as a process to identify and manage use cases (subject to standardization as IEC 62559). WG FSS compiled a smart grid standards list based on SGAM and the smart grid use cases. The list structures the multitude of standards within a common framework reducing the complexity of the standardization landscape. Users of the list may search for appropriate smart grid standards based on their classification by domains, zones and layers (see appendix F for further information on the work of WG SP and WG SGIS as well as the next steps of Mandate M/490).

\subsubsection{Recommended approach for China}

The diversity of stakeholders interested in standardization issues in China has generally increased in recent years. The trend towards RES and more actively involved end consumers of electric power additionally tends to increase the number of stakeholders engaged in smart grid standardization. In particular, new market actors such as the ICT industry are expected to participate actively in order to unfold their innovative potential.

\section{Examples for current standardization activities in China and possible connections to the European Mandate $\mathrm{M} / 490$}

The SGCC Framework and Roadmap for Strong \& Smart Grid Standards [66] stresses the importance of standardization for the smart grid development. Analyzing this document reveals the intention to identify gaps and thereby support the planning and implementation process. The mechanisms and concepts proposed in the context of the Mandate M/490 are appropriate to be taken into consideration for the standardization in China and the coordination and harmonization of activities on the international level.

The issues and aims discussed in the context of the standardization process in China may benefit from coordination with similar activities in the international context. Within the organizational structure of the M/490 SG-CG, possible liaisons with standardization activities in other countries including China are mentioned as future tasks within the scope of Mandate M/490. Therefore a joint discussion on the issues of smart grid standardization may support the design of the smart grid architecture based on a unified planning process and a set of consistent standards.

As the goal of a consistent standardization framework is expressed in context of the SGCC Framework and Roadmap for Strong \& Smart Grid Standards, its structure regarding the standardization system in China may represent a suitable starting point to integrate the European and Chinese viewpoints in context of a common framework. Furthermore, the national smart grid standardization task force established by the Standardization Administration of China (SAC) and NEA about two years ago may also be considered as an organizational platform to address these issues. 
The further promotion of smart grid standardization activities would accelerate the development of an unanimously accepted vision on the technological and organizational design of smart grids in China. Specifically, the integration of new market actors in the standardization process would increase the innovation potential in the smart grid development. Based on the activities of the European Commission, the following policies are worth considering:

\section{- The establishment of an organizational ar-} rangement for smart grid standardization: the Chinese government, for example via MOST, could promote the foundation of an organizational arrangement such as SG-CG to coordinate standardization issues and integrate new market actors in the standardization process. Within this organizational arrangement, clear structures and processes to foster the understanding of the smart grid concept and to provide the means to model and implement smart grid solutions should be defined and implemented. The requirements of smart grids should be analyzed and current and future stakeholders identified.

- The commissioning of a reference architecture framework: the government could engage this organizational arrangement to develop architectural concepts such as a technical reference architecture (i.e. a Chinese Smart Grid Architecture Model). The models applied in this context should be able to describe interoperability aspects of the systems, ranging from business objectives to technical connectivity of the components involved in a solution.

- The commissioning of smart grid use cases and standards: use case descriptions and a thorough process to address governance and quality aspects are beneficial to develop a set of consistent and complimentary smart grid standards. The work of the SG-CG may be regarded as a reference in this area. Moreover, adapting the results of SG-CG to the Chinese context or creating a compatible (mirror-like) approach could serve as the basis to initiate a joint discussion on the issues of smart grid standardization.
Following these recommendations, the key quality requirements of interoperability, data management, and cyber security can then be thoroughly analyzed and managed to create appropriate architecture models and identify supporting smart grid standards. This way, Chinese standardization processes could be synchronized more with international standardization. For example, Chinese standards could be promoted to the international level. Currently, the joint work in standardizing information exchange for demand response and in connecting demand side equipment and/or systems into the smart grid (in IEC PC 118) is a good example for the benefits of such cooperation.

The recommended approach at a glance

- Promote the establishment of an organizational arrangement (e. g. similar to SG-CG) to coordinate smart grid standardization.

- Initiate the development of a reference architecture framework taking into account technical and organizational aspects which are unique to China (i. e. a Chinese Smart Grid Architecture Model).

- Ensure that effective and efficient standardization processes exist and promote the development of smart grid use cases and standards.

\section{References}

1 S. Peltzman, "Toward a More General Theory of Regulation," Journal of Law and Economics, vol. 19, no. 2, pp. 211-240, 1976.

2 G. Brunekreeft, Regulation and Competition Policy in the Electricity Market: Economic Analysis and German Experience, Baden-Baden: Nomos Verlagsgesellschaft $\mathrm{mbH}$, 2003.

3 Department of Energy and Climate Change, "Consultation Outcome - 2050 Pathway Analysis," Government Digital Service, [Online]. Available: https://www.gov.uk/government/consultations/2050-pathways-analysis. [Accessed August 28, 2013].

4 Government of India Planning Commission New Dehli, "Integrated Energy Policy - Report of the Expert Committee," Government of India Planning Commission New Dehli, New Dehli, 2006.

Open Access This chapter is distributed under the terms of the Creative Commons Attribution Noncommercial License, which permits any noncommercial use, distribution, and reproduction in any medium, provided the original author(s) 
5 Ministry of Mines and Energy, "National Energy Plan 2030 (PNE 2030)," Portal Brazil, 2007. [Online]. Available: http:// www.brasil.gov.br/energia-en/planning/national-energyplan-2030-pne-2030. [Accessed August 28, 2013].

6 Federal Ministry for the Environment, Nature Conservation and Nuclear Safety (BMU)/Federal Ministry of Economics and Technology (BMWi), The Federal Government's Energy Concept of 2010 and the Transformation of the Energy System of 2011. Energy Concept for an Environmentally Sound, Reliable and Affordable Energy Supply, Berlin: BMU/BMWi, 2010.

7 J. Nitsch, T. Pregger, Y. Scholz, T. Naegler, M. Sterner, N. Gerhardt, A. von Oehsen, C. Pape, Y.-M. Saint-Drenan and B. Wenzel, "Langfristszenarien und Strategien für den Ausbau der erneuerbaren Energien in Deutschland bei der Berücksichtigung der Entwicklung in Europa und global," Bundesministerium für Umwelt, Naturschutz und Reaktorsicherheit (BMU), Berlin, 2012.

8 The OECD Regulatory Policy Committee, "Recommendations of the Council on Regulatory Policy and Governance," OECD, 2013.

9 S. T. M. Kaplan, "Thinking About Technology: Applying a Cognitive Lens to Technical Change," Research Policy, vol. 37, no. 5, pp. 790-805, 2008.

10 B. Nowak, "Equal Access to the Energy Infrastructure as a Precondition to Promote Competition in the Energy Market. The Case of European Union," Energy Policy, vol. 38, no. 7, pp. 3691-3700, 2010.

11 EU Commission Task Force for Smart Grids Expert Group 3, "EG3 First Year Report: Options on Handling Smart Grid Data," EU Commission , Brussels, 2013.

12 EU Commission Task Force for Smart Grids, Expert Group 3, "Roles and Responsibilities of Actors involved in the Smart Grids Deployment," 2011. [Online]. Available: http:// ec.europa.eu/energy/gas_electricity/smartgrids/doc/expert_group3.pdf. [Accessed May 13, 2014].

13 Bundesnetzagentur für Elekrizität, Gas, Telekommunikation, Post und Eisenbahnen (BNetzA), "Smart Grid" und "Smart Market" - Eckpunktepapier der Bundesnetzagentur zu den Aspekten des sich verändernden Energieversorgungssystems, BNetzA, Bonn, 2011.

14 Bundesnetzagentur für Elektrizität, Gas, Telekommunikation, Post und Eisenbahnen, “Darstellung der Geschäftsprozesse zur Anbahnung und Abwicklung der Netznutzung bei der Belieferung von Kunden mit Elektrizität," 2011. [Online]. Available: http://www.bdew.de/internet.nsf/id/ BBDE5740233A837FC1257830004D9AC0/\$file/Konsolidierte_Lesefassung_GPKE.pdf. [Accessed June 3, 2014].

15 D. Patton, "China's State Grid: Too Big to Work?," NHST Media Group, April 2013. [Online]. Available: http://www.rechargenews.com/magazine/article1321523.ece. [Accessed August 7, 2013].

16 G. Knieps, Wettbewerbsökonomie, Heidelberg: Springer, 2005.

17 F. Sioshansi and W. Pfaffenberger, Electricity Market Reform: An International Perspective, Amsterdam: Elsevier, 2006.
18 S. Stoft, Power System Economics, Piscataway: The Institute of Electrical and Electronics Engineers, 2002.

19 G. Brunekreeft, Regulation and competition policy in the electricity market: economic analysis and German experience, Baden-Baden: Nomos Verlagsgesellschaft $\mathrm{mbH}$, 2003.

20 M. Beesley and S. Littlechild, "The Regulation of Privatized Monopolies in the United Kingdom," The RAND Journal of Economics, vol. 20, no. 3, pp. 454-472, 1989.

21 Deutsche Energie-Agentur (dena), "dena-Verteilnetzstudie - Ausbau und Innovationsbedarf der deutschen Stromverteilungsnetze bis 2030," dena, Berlin, 2012.

22 EYGM Limited, "Mapping Power and Utilities Regulation in Europe," 2013. [Online]. Available: http://www.ey.com/ Publication/vwLUAssets/Mapping_power_and_utilities_ regulation_in_Europe/\$File/Mapping_power_and_ utilities_regulation_in_Europe_DX0181.pdf. [Accessed June 4, 2014].

23 The Regulatory Assistance Project, "Electricity Regulation in the US: A Guide," 2011. [Online]. Available: http://www. raponline.org/documents/download/id/645. [Accessed June 4, 2014].

24 Roland Berger Strategy Consultants, "The Structuring and Financing of Infrastructure Projects, Financing Gaps and Recommendations Regarding the New TEN-E Financial Instrument," European Commission Directorate General for Energy, Brussels, 2011.

25 Office of Gas and Electricity Markets (OFGEM), "Handbook for Implementing the RIIO Model," OFGEM, London, 2010.

26 Deutsche Energie-Agentur (dena), "Dena Grid Study II. Integration of Renewable Energy Sources into the German Power Supply System until 2020," 2011. [Online]. Available: http://www.dena.de/fileadmin/user_upload/ Publikationen/Erneuerbare/Dokumente/Flyer_dena_Grid_ Study_II_Englisch.pdf. [Accessed August 26, 2013].

27 Bundesnetzagentur für Elektrizität, Gas, Telekommunikation, Post und Eisenbahnen (BNetzA), "Monitoringsbericht 2012," BNetzA, Bonn, 2012.

28 A. McCrone, E. Usher, V. Sonntag-O'Brien, U. Moslener and C. Grüning, "Global Trends in Renewable Energy Investment 2012," Frankfurt School of Finance and Management gGmbH, Frankfurt, 2012.

29 G. Brunekreeft and E. Ehlers, “Does Ownership Unbundling of the Distribution Networks Distort the Development of Distributed Generation?,"Tilburg University, Tilburg, 2005.

30 The European Parliament and the Council of the European Union, "Directive 2009/72/EC of the European Parliament and of the Council of 13 July 2009 Concerning Common Rules for the Internal Market in Electricity and Repealing Directive 2003/54/EC," Official Journal of the European Union, Brussels, 2009.

31 Mitteldeutsche Netzgesellschaft Strom mbH, "Gemeinsamer Netzausbauplan der 100 kV Verteilnetzbetreiber der Regelzone 50Hertz," 0407 2013. [Online]. Available: http:// www.forum-netzintegration.de/uploads/media/Schulze_ NAP110kV_RZ_50Hz.pdf. [Accessed May 20, 2014]. 
32 European Network of Transmission System Operators for Electricity (ENTSO-E),"10-Year Network Development Plan 2012," ENTSO-E, Brussels, 2012.

3350 Hertz Transmission GmbH; Amprion GmbH; TenneTTSO $\mathrm{GmbH}$; Transnet BW GmbH, "Wie funktioniert die Erstellung des Netzentwicklungsplans?," CB.e Clausecker | Bingel AG, [Online]. Available: http://www.netzentwicklungsplan. de/content/wie-funktioniert-die-erstellung-des-netzentwicklungsplans. [Accessed November 27, 2013].

34 U. Hansen, "How is Network Development Progressing in Germany?," Bundesnetzagentur für Elektrizität, Gas, Telekommunikation, Post und Eisenbahnen (BNetzA), Berlin, 2012. [Online]. Available: http://enree.com/fileadmin/user_ upload/Downloads/Konferenzen/Netzintegration_2012/ Vortraege/4_Ulrike_Hansen.pdf. [Accessed May 4, 2014].

35 K. Schäfer, "Challenges and Solutions in the Expansion and Modernisation of the Power Grids in Germany," Bundesministerium für Wirtschaft und Technologie (BMWi), Berlin, 2013.

36 Bundesministerium für Wirtschaft und Energie, "Plattform zukunftsfähige Energienetze - Arbeitsgruppen," Bundesministerium für Wirtschaft und Energie, 2014. [Online]. Available: http://www.bmwi.de/DE/Themen/ Energie/Netzausbau/plattform-zukunftsfaehigeenergienetze,did=595614.html. [Accessed June 2, 2014].

37 E. Binda Zane, R. Brückmann, D. Bauknecht, F. Jirouš, R. Piria, N. Trennepohl, J. Bracker, R. Frank and J. Herling, "Integration of Electricity from Renewables to the Electricity Grid and to the Electricity Market - RES-INTEGRATION," 2012. [Online]. Available: http://www.oeko.de/ oekodoc/1378/2012-012-en.pdf. [Accessed September 30, 2013].

38 Verband der Elektrotechnik Elektronik Informationstechnik e. V. (VDE), "Technische Bedingungen für Anschluss und (Parallel-)Betrieb von Anlagen direkt angeschlossener Kunden an das Niederspannungs-, Mittelspannungs- und Hochspannungsnetz," 2012. [Online]. Available: http:// www.vde.com/de/fnn/arbeitsgebiete/tab/Seiten/tab.aspx. [Accessed September 30, 2013].

39 The European Parliament and the Council of the European Union, "Directive 2001/77/EC of the European Parliament and of the Council of Sept. 27, 2001, Promotion of Electricity Produced from Renewable Energy Sources in the Internal Electricity," Official Journal of the European Communities, Brussels, 2001.

40 The European Parliament and the Council of the European Union, "Directive 2009/28/EC of the European Parliament and of the Council of Apr. 23, 2009, On the promotion of the use of energy from renewable sources," Official Journal of the European Union, Brussels, 2009.

41 European Network of Transmission System Operators for Electricity (ENTSO-E), “ENTSO-E Network Code for Requirements for Grid Connection Applicable to all Generators," ENTSO-E, Brussels, 2013.

42 Clearingstelle EEG, "English," Clearingstelle EEG, [Online]. Available: https://www.clearingstelle-eeg.de/english. [Accessed March 7, 2014].
43 J. Hiscock, "Spotlight on Advance Metering Infrastructure," International Smart Grid Action Network, 2013.

44 E. Mahnke and J. Mühlenhoff, "Strom speichern," Agentur für Erneuerbare Energien e. V. , Berlin, 2010.

45 C. Marnay, N. Zhou, M. Qu and J. Romankiewicz, "International Microgrid Assessment: Governance, Incentives, and Experience," Berkeley National Laboratory, Berkeley, 2013.

46 L. Xu and J. Alleyne, "Microgrid, One of the Chinese Puzzles in Smart Grid," 2012. [Online]. Available: http://www. sgtresearch.com/uploads/soft/120729/Microgrid-oneof-the-Chinese-Puzzles-in-Smart-Grid_SGT-Research.pdf. [Accessed September 30, 2013].

47 U.S. Department of Energy (USDOE), "Economic Impact of Recovery Act Investments in the Smart Grid," USDOE, Washington D.C., 2013.

48 P. Savage, R. Nordhaus and S. Jamieson, "DC Microgrids: Benefits and Barriers," Yale School of Forestry \& Environmental Studies, Falls Village, 2010.

49 National Bureau of Statistics of the People's Republic of China, China Energy Statistical Yearbook, Beijing: China Statistics-Press, 2012.

50 Azure International , "Azure China Cleantech Update," Azure International , 2013.

$51 \mathrm{X}$. Qiu and H. Li, "Energy Regulation and Legislation in China," Environmental Law Reporter, no. 7, pp. 1067810693, 2012.

52 Deutsches Institut für Normung e. V. (DIN), “Die deutsche Normungsstrategie aktuell," DIN, Berlin, 2009.

53 Die Bundesregierung, "Normungspolitisches Konzept der Bundesregierung," 2009. [Online]. Available: http://www. bmwi.de/BMWi/Redaktion/PDF/M-O/normungspolitisches-konzept-der-bundesregierung,property=pdf,bere ich=bmwi2012,sprache $=$ de,rwb=true.pdf. [Accessed February 19,2014$]$.

54 CEN-CENELEC-ETSI Smart Grid Coordination Group, "Sustainable Processes," European Committee for Standardization, Brussels, 2012.

55 CEN-CENELEC-ETSI Smart Grid Coordination Group, "Framework Document," European Committee for Standardization, Brussels, 2012.

56 CEN-CENELEC-ETSI Smart Grid Coordination Group, "Smart Grid Reference Architecture," European Committee for Standardization, Brussels, 2012.

57 The GridWise Architecture Council, "GridWise Interoperability Context - Setting Framework," 2008. [Online]. Available: http://www.gridwiseac.org/pdfs/interopframework_ v1_1.pdf. [Accessed September 30, 2013].

58 Federal Energy Regulatory Commission (FERC), "What FERC does," FERC, May 2013. [Online]. Available: https:// www.ferc.gov/about/ferc-does.asp. [Accessed December 3, 2013].

59 Legal Information Institute, "42 USC $§ 7172$ - Jurisdiction of Commission," Cornell University Law School, [Online]. Available: http://www.law.cornell.edu/uscode/text/42/7172. [Accessed December 3, 2013].

60 Electric Power Research Institute, "Advanced Metering Infrastructure (AMI)," 2007. [Online]. Available: https://www. 
ferc.gov/EventCalendar/Files/20070423091846-EPRI\%20 -\%20Advanced\%20Metering.pdf. [Accessed February 18, 2014].

61 Eurelectric, "Public Consultation on Use of Spectrum for More Efficient Energy Production and Distribution," Eurelectic Response Paper, Brussels, 2012.

62 Bundesministerium für Umwelt, Naturschutz und Reaktorsicherheit (BMU), "Act on Granting Priority to Renewable Energy Sources," 2013. [Online]. Available: http://www. erneuerbare-energien.de/fileadmin/Daten_EE/Dokumente_PDFs_/eeg_2013_bf.pdf. [Accessed February 20, 2014].

63 D. Ernst, "Toward Greater Pragmatism? China's Approach to Innovation and Standardization," 2011. [Online]. Available: http://igcc.ucsd.edu/assets/001/502077.pdf. [Accessed February 19, 2014].

64 A. Updegrove, "The Role of Government in ICT Standardization," Consortium Standards Bulletin, vol. 6, no. 2, 2007.

65 The European Commission, "M/490 Standardization Mandate to European Standardisation Organisations (ESOs) to Support European Smart Grid Deployment,"The European Commission, Brussels, 2011.

66 State Grid Corporation of China (SGCC), Framework and Roadmap for Strong \& Smart Grid Standards, Beijing: SGCC, 2010. 